\title{
Feasibility of introducing a comprehensive package of antenatal care services in rural public clinics in South Africa
}

\author{
Jane Chege \\ Population Council \\ Ian Askew \\ Population Council \\ Nzwakie Mosery \\ Mbali Ndube-Nxumalo \\ Busi Kunene
}

See next page for additional authors

Follow this and additional works at: https://knowledgecommons.popcouncil.org/departments_sbsr-rh

Part of the Demography, Population, and Ecology Commons, International Public Health Commons, Maternal and Child Health Commons, Public Health Education and Promotion Commons, and the Women's Health Commons

How does access to this work benefit you? Let us know!

\section{Recommended Citation}

Chege, Jane, Ian Askew, Nzwakie Mosery, Mbali Ndube-Nxumalo, Busi Kunene, Mags Beksinska, Janet Dalton, Ester Snyman, Wilem Sturm, and Preshny Moodley. 2005. "Feasibility of introducing a comprehensive package of antenatal care services in rural public clinics in South Africa," FRONTIERS Final Report. Washington, DC: Population Council. 


\section{Authors}

Jane Chege, lan Askew, Nzwakie Mosery, Mbali Ndube-Nxumalo, Busi Kunene, Mags Beksinska, Janet Dalton, Ester Snyman, Wilem Sturm, and Preshny Moodley 


\section{Feasibility of Introducing a Comprehensive Integrated Package of Antenatal Care Services in Rural Public Clinics in South Africa}

FRONTIERS: Jane N. Chege, Ian Askew

Reproductive Health Research Unit: Nzwakie Mosery, Mbali Ndube-Nxumalo, Busi Kunene, Mags Beksinska

KwaZulu-Natal Department of Health, Janet Dalton, Ester Snyman

Department of Microbiology and Infectious Diseases, University of Natal, Wilem Sturm, Preshny Moodley

August 2005

This study was funded by the U.S. AGENCY FOR INTERNATIONAL DEVELOPMENT (USAID) under the terms of Cooperative Agreement Number HRN-A-00-98-00012-00 and Population Council in-house project 8011 13058. The opinions expressed herein are those of the authors and do not necessarily reflect the views of USAID. 


\section{SUMMARY}

To address and improve the quality of antenatal care provided in its clinics, the Maternal Child and Women's Health (MCWH) Unit of the KwaZulu-Natal (KZN) DOH decided to review and revise the way it provides antenatal care services. Informed by research conducted by WHO on focused antenatal care, this revised approach consists of five goal-directed ANC visits and two post-natal care visits. The MCWH Unit, in collaboration with the Population Council's FRONTIERS in Reproductive Health (FRONTIERS) Program, the Reproductive Health Research Unit (RHRU) of the University of Witwatersrand, and the Department of Medical Microbiology and Infectious Diseases of the Nelson Mandela School of Medicine, University of Natal, developed and then pilot-tested this revised model in Ulundi District of KwaZulu-Natal Province. The project's objective was to develop and test an improved and integrated antenatal care programme for public sector clinics that will increase the range and quality of services received by pregnant women and improve their reproductive health behaviour and status.

The focused package integrated the following additional services into routine ANC service provision: STI prevention counselling, diagnosis and management using the syndromic approach; onsite syphilis screening and same-day results; and HIV prevention information, including prevention of mother-to-child transmission (PMTCT), and referral for VCT either within the clinic or to the referral hospital where VCT was not available onsite. The KZN $\mathrm{DOH}$ introduced the package through in-service training of staff, and the supply of essential equipment and supplies required to provide quality ANC services.

Using a pre and post-test comparison group design, 12 public clinics in two rural districts were purposively selected and six each allocated to the intervention and comparison groups. Data were collected through client-provider observations and exit interviews with new and repeat ANC clients, a clinic inventory and interviews with staff. The study was conducted between April 2002 and August 2003. The study assessed the feasibility and acceptability of introducing the re-organized ANC model and sought to determine its impact on the quality of care and on client and provider satisfaction; there was also a nested study to assess the introduction of on-site maternal syphilis screening, the results of which will be presented separately.

Introduction of the intervention activities themselves was feasible. Various problems were encountered, however, during and immediately after introduction that influenced the clinics' capacity to implement and sustain the re-organized services, such as trainer and staff turnover. This implies that efforts to scale-up or replicate this model must consider such resource issues, and that other support systems, such as staff supervision and educational materials, also need attention.

Overall there was no detrimental effect on staff morale; indeed, improvements in clinic preparedness to offer ANC services reduced some concerns about working conditions. Client satisfaction was already quite high and did not improve further following the intervention.

The straightforward services for monitoring and managing the physical progress of pregnancy were already being provided satisfactorily, and these were sustained. There were, however, some problems as the proportion of women receiving counselling on nutrition in pregnancy, on birth planning, on breastfeeding and on postpartum family planning were insufficient at endline, even though there were some increases attributable to the intervention. Of particular concern was that even though the proportion of first visit clients who were assessed for at least one pregnancy danger sign increased slightly over time, the mean Feasibility of introducing a comprehensive integrated package of antenatal care services in rural public clinics in South Africa 
number of danger signs assessed reduced significantly in the intervention clinics, with women being counselled on less than two out of a possible eight signs.

Among the additional services offered, the proportion of ANC clients receiving STI and/or HIV services doubled in the intervention clinics. However, the proportions of women receiving these services remained well below the universal coverage expected; of particular concern is the fact that less than one-third of pregnant women were informed about PMTCT and VCT, despite rollout of the national PMTCT programme at the same time as this intervention. Moreover, the content of the additional services provided in the intervention clinics primarily included an external genital exam, discussion of STI symptoms and condom use for STI prevention - there was no increase in assessing a client's personal risk for STIs, including presence of symptoms (although these did increase in the comparison clinics). Introduction of the on-site syphilis testing also suffered some setbacks, but once introduced, preliminary results suggest that this service appears to have been sustained.

Although these results are disappointing, it is important to bear in mind that despite the intervention activities being introduced pretty much according to plan, immediate staff turnover and inadequate supervision meant that only two of the six intervention clinics had at least one staff member who had covered all the training modules at the time of the endline survey. As staff were either not being replaced, or their replacements not trained in the new ANC model, it is not possible, or valid therefore, to conclude from these findings whether implementation of the intervention did or did not improve the quality of care. This is because, following its introduction, staffing problems meant that the intervention could not continue to be implemented as intended.

It is possible to conclude, however, that interventions such as this, that rely heavily on training staff in new ways of organizing and providing services, must develop and use training and supervisory strategies or systems that are explicitly designed to incorporate relatively rapid rates of staff turnover. This may mean developing the capacity of the clinic staff, or of the supervisor responsible for monitoring ANC services in the clinic, to ensure that if a trained staff member leaves someone either replaces them that has the same technical competence, or the replacement undergoes immediate training in the ANC model being implemented at that clinic. This study also highlights the importance of paying attention to health systems when introducing revised or new services, especially HIV-related services. 


\section{CONTENTS}

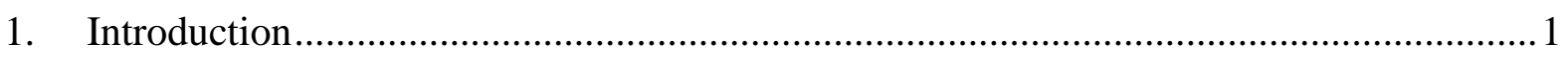

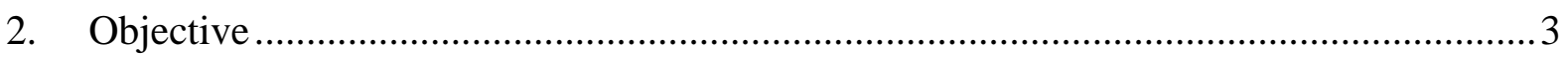

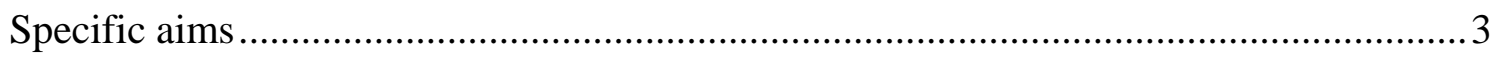

3. Comprehensive Focused Care Package ….......................................................................

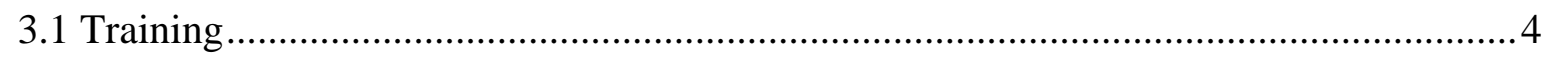

3.2 Problems Encountered during Implementation of Interventions .................................... 8

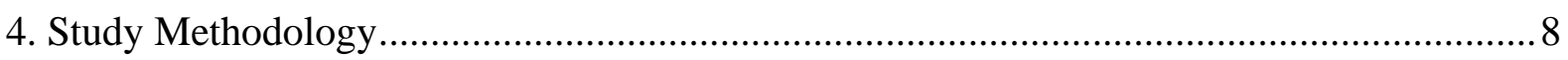

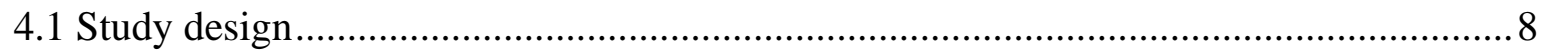

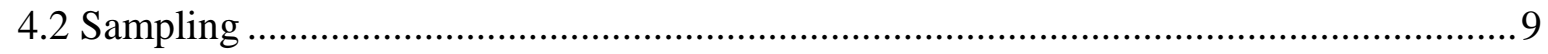

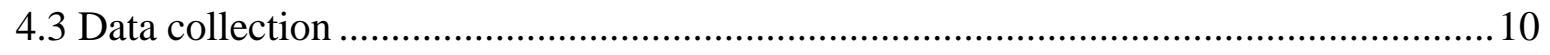

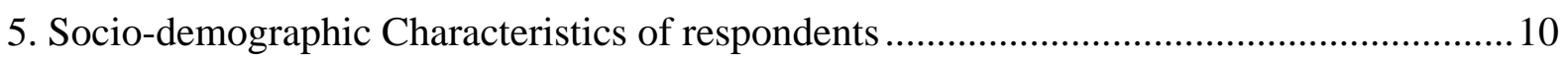

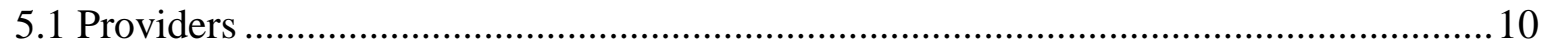

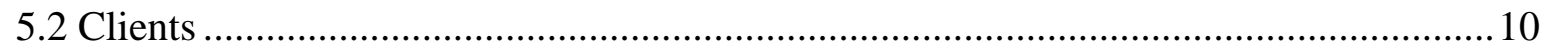

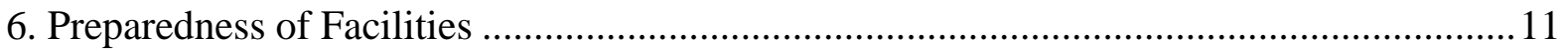

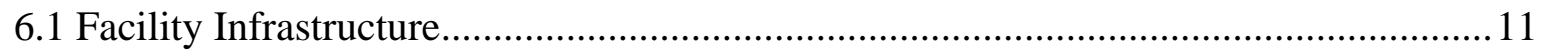

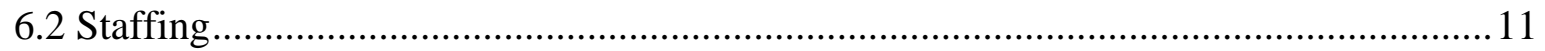

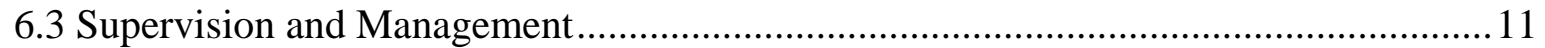

6.4 Availability of IEC Materials, Protocols and Guidelines ...........................................12

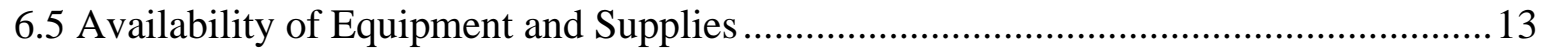

6.5.1 Availability and Functioning of Equipment ....................................................... 13

6.5.2 Availability of Essential Drugs, Vaccines and Supplies........................................ 14

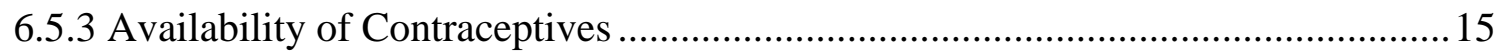

6.6 Summary Measures of Clinic Preparedness ................................................................ 16

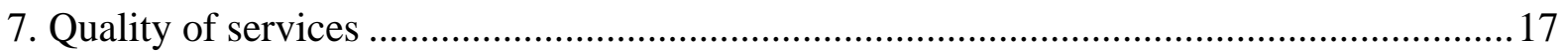

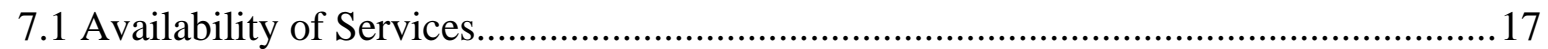

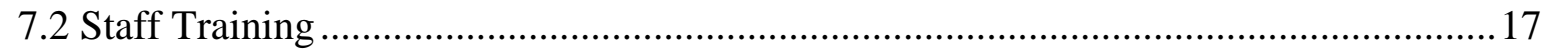

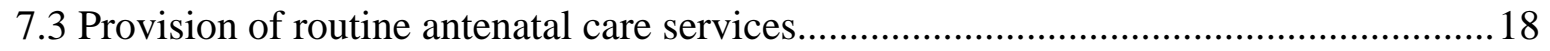

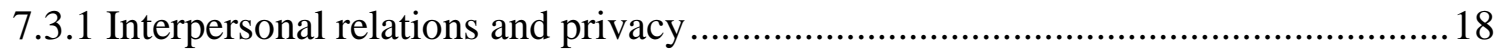

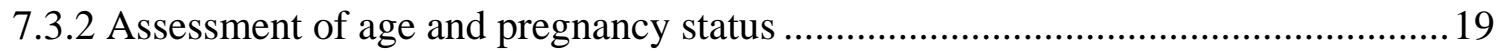

7.3.3 Risk assessment and counselling on pregnancy danger signs .............................19

7.3.4 Physical assessments and blood tests................................................................20

7.3.5 Tetanus immunization and Folic Acid/ Ferrous Sulphate Supplements.................21

7.3.6 Nutrition and Birth Preparedness Advice .............................................................. 22

Feasibility of introducing a comprehensive integrated package of antenatal care services in rural public iii clinics in South Africa 


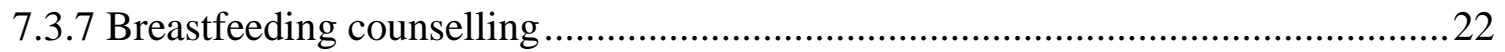

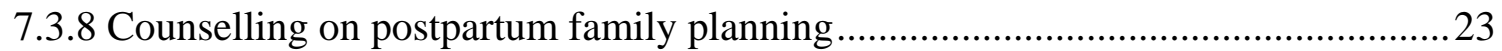

7.4 Integration of STI prevention and management services .........................................23

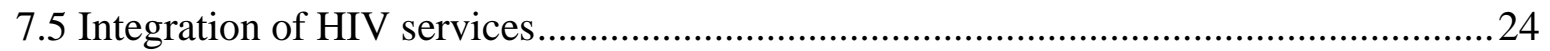

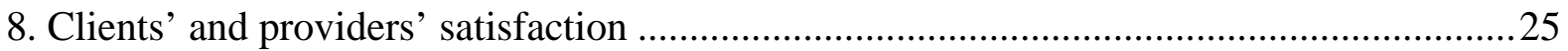

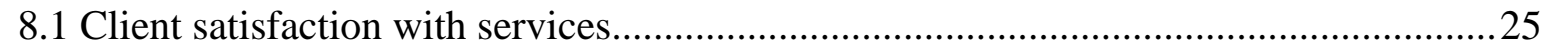

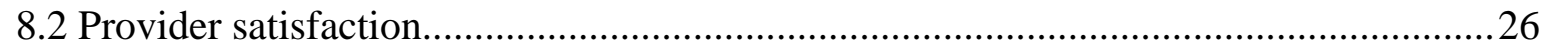

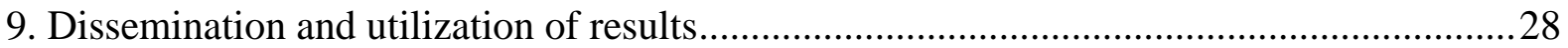

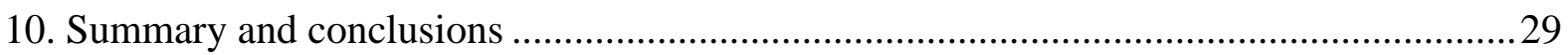

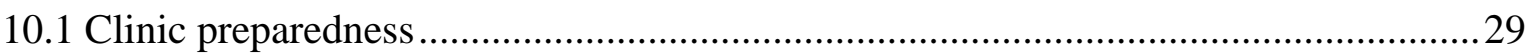

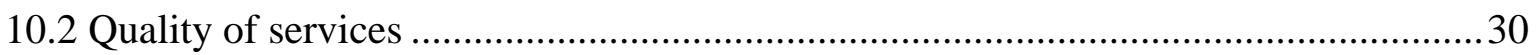

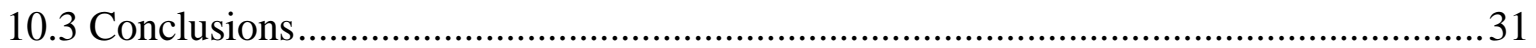

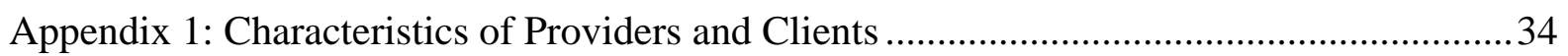

Appendix 2: Recommendations From Dissemination Workshop Participants........................37

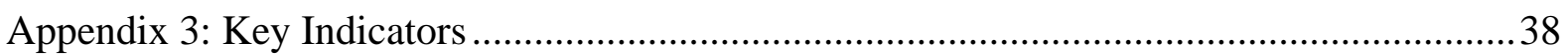

Appendix 4: Field Data Collection Team ..................................................................... 40 


\section{ACKNOWLEDGMENTS}

We are greatly indebted to Ms Noel Philips and Dr. Ndugga Maggwa for their invaluable input in designing the intervention study that forms the basis of this report; to Ms. Irmeli Arsalo for her role in designing the training modules and training the master trainers; Maya Gokul for her role in the STI and FP training, Fezana Karim for conducting the RPR test training and Jabu Hlazo for her support in training research assistants and supervising the fieldwork. Our sincere gratitude to Mrs. D.T. Memela, Zululand District Acting Manager and her project implementation team for their support and effort in addressing challenges in the implementation of the interventions; thanks to Mrs. Sizathu Mbabo, MCWH Coordinator, for her valuable contribution to the project.

This study would not have been a success without the tireless effort of the data collection team (appendix 4) and all the clinic managers, services providers and antenatal care clients from the 12 study clinics who gave consent, support and contributed their valuable time to respond to the interviews.

Last but not least, we acknowledge the contribution of FRONTIERS and USAID staff for providing valuable input to the study and completion of the final report. Thank you John Townsend, Joanne Gleason, Melinda Wilson, Shawn Malarcher and Mary Ellen Stanton. 


\section{LIST OF TABLES AND FIGURES}

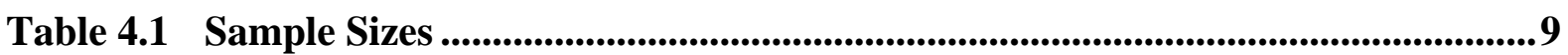

Table 6.1 Numbers of Clinics Having Guidelines and Protocols ..................................13

Table 6.2 Numbers of Clinics Having IEC Materials .................................................13

Table 6.3 Numbers of clinics having equipment in working order.................................14

Table 6.4 Numbers of clinics having essential supplies..................................................15

Table 6.5 Numbers of Clinics Having Stock-outs in Various Contraceptives ...............16

Table 6.6 Mean Preparedness Scores by Site..................................................................16

Table 7.1 Number of staff receiving training as part of basic training ..........................18

Table 7.2 Proportions of first visit clients assessed for and provided information and counselling on pregnancy danger signs..........................................................20

Table 7.3 Proportion of clients provided information about specimen taken and medications given by type of clinic.............................................................221

Figure 7.1 Proportion of first visit clients with whom providers discussed aspects of a

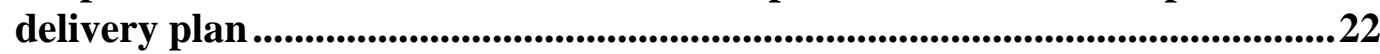

Table 7.4 Proportion of clients with whom the provider discussed breastfeeding options.

Table 7.5 Proportion of clients with whom the provider discussed various family planning methods.

Table 7.6 Proportion of first visit clients receiving STI-related information or services 24

Table 7.7 Proportion of first visit clients receiving HIV-related information or services 25

Table 8:1 Clients' satisfaction with clinic services........................................................26

Figure 8.1 Providers' levels of job satisfaction................................................................27

Figure 8.2 Issues that providers feel should be addressed .............................................28 


\section{ABBREVIATIONS AND ACRONYMS}

AIDS

ANC

ATT

BCG

$\mathrm{BP}$

$\mathrm{DoH}$

DPT

DT

EC

FP

$\mathrm{Hb}$

HIP

HIV

IEC

IUCD

KZN

MCHW

MTCT

NGO

PMTCT

$\mathrm{RH}$

RHRU

RTI

SADHS

STIs

USAID
Acquired Immune Deficiency Syndrome

Antenatal care

Anti tetanus toxoid

Bacille Calmette Guerin

Blood pressure

Department of Health

Diptheria, Pertussis, Tetanus

Diptheria, Tetanus

Emergency contraceptive

Family planning

Haemoglobin

Haemophilus Influenza B

Human Immunodeficiency Virus

Information, education and communication

Intra-uterine contraceptive device

KwaZulu-Natal

Maternal child and women's health

Mother to child transmission

Non-Government Organization

Prevention of mother to child transmission

Reproductive health

Reproductive Health Research Unit

Reproductive tract infection

South African Demographic and Health Survey

Sexually Transmitted Infections

United States Agency for International Development 


\section{Introduction}

Access to maternity services is relatively good in South Africa: 94 percent of pregnant women receive antenatal care from a doctor or midwife, and the vast majority (84\%) have skilled attendance during delivery (SDHS, 1998). However, maternal and infant morbidity and mortality rates remain high relative to other countries with a similar level of development. In 2000, the infant mortality rate was 56/1,000 live births (Saving Babies, 2000) and maternal mortality was between 175-200/100,000 (Saving Mothers, 1999-2001). There are striking differences in maternal mortality rates between racial groups, with African women accounting for the majority of deaths (92.6\%) compared to 4.4 percent, 0.9 percent and 0.7 percent for Coloured, White and Indian women respectively (Saving Mothers, 1998).

The Saving Mothers Report (1999-2001) and the Perinatal Care Survey of South Africa (Saving Babies, 2000) underline a number of avoidable factors, missed opportunities and quality of care factors that account for a significant proportion of maternal and perinatal deaths respectively. Patient or community-related factors, such as not attending antenatal care and delays in seeking help accounted for over half (54\%) of maternal deaths, and 42 percent of deaths were due to health system factors, over half of which were provider-related, such as poor assessment and diagnosis, failure to follow standard protocols and poor monitoring of patients. The Perinatal Care Survey found that 36 percent of perinatal deaths were a result of patient-related factors, such as lack of antenatal care, late initiation of antenatal care or infrequent attendance at antenatal clinics.

As many as 60 percent of maternal deaths were caused by factors that could have been detected and addressed during the antenatal period (Saving Mothers, 1998), such as hypertension, ante- and post-partum haemorrhage, abortion, ectopic pregnancy, and pregnancy-related sepsis. Failure to detect and address these causes in time was due to several factors, including the client seeking ANC services late in the pregnancy, and poor management of the client at the health facility.

Causes of maternal death are changing over time, with non-pregnancy related infections (mainly due to HIV/AIDS) increasing from 23 percent in 1998 to 34 percent in 2001, which is now the most frequent cause of maternal death. South Africa has one of the most rapidly growing HIV epidemics in the world, with a national prevalence of 15.6 percent among persons aged 15-49 years and 5.6 percent among children aged 2-14 years (Nelson Mandela/HSRS 2001). The Department of Health (DOH) antenatal survey in 2001 indicated a national prevalence of 27.8 percent among antenatal clients, with KwaZulu-Natal Province having the highest level at 37 percent. Currently the $\mathrm{DOH}$ is expanding provision of voluntary counselling and testing (VCT) for HIV services. Roll-out of Nevirapine provision to HIV positive pregnant women began in 2000 in some hospitals as part of the DOH's effort to reduce mother-to-child transmission (MTCT) of HIV, and in 2004 the DOH started providing anti-retroviral drug treatment in some hospitals for patients with symptoms of AIDS and/or who have a CD4 count of less than 200 (DOH, 2003).

Hypertension in pregnancy is the most frequent pregnancy-related cause of maternal mortality $\left(18 \%\right.$ in $\left.2000^{1}\right)$. Both the Maternal Care guidelines and the Policy and Management of Guidelines for Common Causes of Maternal Deaths have clear guidance on prevention and

\footnotetext{
$1 \quad$ Other causes of maternal mortality are obstetric haemorrhage (14\%), pregnancy-related sepsis (9\%), acute collapse and embolism (7\%), pre-existing medical conditions (6\%), early pregnancy death (5\%), and anaesthetic-related (3\%).
} 
management of hypertension and hypertension-related complications (all women should have their blood pressure checked and their urine tested for protein or glucose). All pregnant women should also receive ferrous sulphate tablets (200 mg daily) to prevent anaemia, and folic acid tablets ( $5 \mathrm{mg}$ daily) during the first trimester of pregnancy to help prevent foetal neural tube defects. Tetanus toxoid immunization must be given to prevent neonatal tetanus (in areas where neonatal tetanus is still prevalent) (DOH, 2000); however, only 59 percent of women received at least one tetanus toxoid injection during pregnancy (SDHS, 1998).

The national guidelines emphasise the importance of diagnosing and treating pregnant women for reproductive tract infections (RTIs) using the syndromic approach, and screening all women for syphilis using the rapid plasma reagin (RPR) test. Management and control of RTIs, and especially sexually transmitted infections (STIs), is important because they can cause pregnancy-related complications (foetal wastage, premature births, congenital infections, ectopic pregnancy) and complications in the neonate and infant (blindness, pneumonia, congenital syphilis); they are also associated with increased HIV transmission (Grosskurth et al. 1995; Auvert et al. 2001; Buvé et al 2001; Cameroon et al 1989; Fleming and Wasserheit 1999). STIs in pregnancy are a major problem in South Africa; surveys in KwaZulu-Natal found that 52 percent of antenatal clients had at least one STI (gonorrhoea, chlamydia, syphilis, or trichomoniasis).

Despite these guidelines, the Saving Babies report in 2000 identified lack of testing for syphilis, delayed or no referral of patients with hypertension, poor obstetric history and poor response to poor or excessive uterine growth as the common factors leading to perinatal deaths that would be avoidable if the quality of ANC is improved. The survey found that for 38 percent of perinatal deaths due to syphilis, the clinic did not perform the screening test and in another 16 percent, women who tested positive did not receive treatment (Saving Babies, 2000). The survey also found that only one-third of facilities have on-site syphilis testing and consequently the average turn around for test results is 11 days.

Although the contraceptive prevalence rate is high in South Africa compared to other SubSahara African countries, limitations in promotion and use of modern contraception have been observed. Abortion is a reflection of method failure, lack of access, or individual lack of interest in using contraception. Abortion was the cause of 5.7 percent and 3.9 percent of maternal deaths in South Africa in 1998 and 2000 (DOH, 2000), respectively, despite it being legal. The 1998 Report on Confidential Enquiries into Maternal Deaths observed that women aged 30 years and older or with a parity of 5 or more were at greater risk of death during pregnancy and the puerperium than their younger and lower parity counterparts, and recommended intensification of education about dangers of pregnancy for older women and women of high parity, as well as active promotion of family planning in these groups during ANC visits.

To address and improve the quality of antenatal care, the Maternal Child and Women's Health (MCWH) Unit of the KwaZulu-Natal (KZN) DOH decided to review and revise the way it provides antenatal care services. Informed by two studies conducted by WHO (Villar et al, 2001; Carroli. et al, 2001) that have demonstrated that it is possible to reduce the number of antenatal visits and to focus each visit on specific services without compromising the acceptability and quality of care or increasing the likelihood of adverse pregnancy outcomes, this revised approach consists of five goal-directed ANC visits and two post-natal care visits. The MCWH Unit, in collaboration with the Frontiers in Reproductive Health (FRONTIERS) Program of the Population Council, the Reproductive Health Research Unit (RHRU) of the University of Witwatersrand, and the Department of Medical Microbiology 
and Infectious Diseases of the Nelson Mandela School of Medicine, University of Natal, developed and then pilot-tested this package of comprehensive and focused antenatal care services in Ulundi District of KwaZulu-Natal Province.

\section{Objective}

To develop and test an improved and integrated antenatal care programme for public sector clinics that will increase the range and quality of services received by pregnant women and improves their reproductive health behaviour and status.

\section{Specific aims}

1. To assess the feasibility and acceptability of implementing an improved and integrated package of ANC services.

2. To assess the impact of training of ANC providers on their ability to provide quality integrated ANC services.

3. To assess the feasibility, acceptability, quality and incremental cost of introducing onsite syphilis screening by ANC providers at the clinic level.

4. To assess the effect of the improved ANC package on client and provider satisfaction with antenatal services.

\section{Comprehensive Focused Care Package}

The revised package of antenatal care is described in the accompanying table. Following the focused model proposed by WHO, the package comprises five antenatal visits at specific times. Each visit is expected to focus on certain services that are relevant for the gestational age of the woman at that visit. Two postnatal visits are also recommended. The package includes the routine services that were already recommended and some additional or special services that were felt to be important and so have been introduced at specific visits. The focused package aims to provide comprehensive ANC services by integrating the following services into routine ANC service provision:

- STI prevention counselling, diagnosis and management using the syndromic approach.

- Onsite syphilis screening using the RPR test ${ }^{2}$. All first visit ANC clients should have their blood drawn for onsite syphilis screening and receive their results the same day.

- HIV prevention information, including prevention of mother-to-child transmission (PMTCT), and referral for VCT either within the clinic or to the referral hospital where VCT was not available onsite.

The KZN DOH introduced the package through in-service training of staff, and the supply of all essential equipment and supplies required to provide quality ANC services; these needs were identified during the baseline survey.

2 As a component of the research study, part of the blood specimen taken from the clients and the clinic RPR results were transported to the referral hospital laboratory for verification, quality check and feedback to the clinic. 


\subsection{Training}

Training of providers followed the training of trainers (TOT) approach and used modular training. The KZN DOH identified master trainers who were Primary Health Care (PHC) Supervisors, PHC Trainers, and Advanced Midwives or professional nurses experienced in antenatal care in the intervention district. A DOH trainer covered all the training modules apart from the FP and STI modules, which were covered by RHRU staff, and training in RPR testing, which was conducted by the University Department of Medical Microbiology staff. Training of trainers took place between April and June 2002. The master trainers met at the district health office for two days each month and covered one of the six training modules per day. For training in the RPR test, the master trainers were trained at the University laboratories in Durban in December 2002. The master trainers were expected to train the nurses immediately after completing the modules, and so there was a break of two weeks after completion of each module (apart from RPR testing) to allow the master trainers to "cascade" the skills transfer on each module to the clinics.

The key areas of the training were:

- Reduce visits to five antenatal and two post-natal, with each visit having a set number of stipulated activities.

- Prevention, screening for and management of health conditions likely to increase the risk of adverse pregnancy outcomes (e.g. monitoring blood pressure and weight, clinical exam to detect early warning signs, urinalysis and microscopy of urine, immunization against tetanus, iron and folic acid supplements).

- Screening and management of STIs using the syndromic approach.

- Individualized and group counselling and health education sessions on physiological process of pregnancy and childbirth, recognizing pregnancy risk factors and appropriate health seeking behaviour, appropriate nutrition, personal hygiene and exercise, STIs and HIV prevention behaviours, mother-to-child transmission of HIV, Voluntary Counselling and Testing (VCT) for HIV, postpartum FP.

- Discuss delivery plan.

- Referral for VCT.

- Onsite syphilis testing using RPR tests.

The training in RPR testing covered theory (including definition of syphilis, causative organism, primary, secondary, tertiary and congenital syphilis) and demonstration on how to conduct the RPR test. The project designed triplicate forms for delivering the blood and clinic results to the labs for quality check to ensure that a copy was left at the clinic and another at the lab, and one copy with confirmatory lab results was taken back to the clinic.

Ongoing monitoring of the introduction and implementation of this package was undertaken through visits by the Project Intervention Coordinator to the study clinics, through regular feedback from the staff-in-charge at the clinics, checking availability of specific equipment and supplies and through observing the providers at work. This component of the study is being reported separately. 


\section{KwaZulu-Natal Comprehensive Antenatal / Postnatal Care Package}

\begin{tabular}{|c|c|c|c|c|c|}
\hline $\begin{array}{c}\text { ANC } \\
\text { VISITS }\end{array}$ & TIME OF VISIT & $\begin{array}{c}\text { ROUTINE ANTENATAL CARE } \\
\text { SERVICES }\end{array}$ & $\begin{array}{c}\text { ADDITIONAL } \\
\text { or SPECIAL SERVICES }\end{array}$ & $\begin{array}{c}\text { CONTENT OF } \\
\text { HEALTH EDUCATION }\end{array}$ & SKILLS NEEDED \\
\hline FIRST & $\begin{array}{l}\text { Between } \\
\text { 8-20 weeks } \\
\text { First visit as early } \\
\text { as possible should } \\
\text { be recommended }\end{array}$ & $\begin{array}{ll}- & \text { Pregnancy confirmation } \\
- & \text { Personal details } \\
- & \text { Full physical examination } \\
- & \text { Medical history } \\
- & \text { Details of previous } \\
& \text { pregnancies and maternal } \\
& \text { diseases } \\
- & \text { Hb and RPR on-site with } \\
& \text { appropriate treatment } \\
- & \text { Iron/ folic acid } \\
& \text { supplementation } \\
- & \text { Rh-factor } \\
- & \text { BP/weight/height } \\
- & \text { Urine (protein and glucose) } \\
- & \text { Gestational age and EDD } \\
- & \text { Bi-manual palpation } \\
- & \text { SFH } \\
- & \text { FHB, (at } 12^{\text {th }} \text { week if Sonic } \\
& \text { aid), after } 18 \text { weeks gestation } \\
- & \text { Vaginal examination and } \\
- & \text { STD-management } \\
- & \text { Tetanus } 1 / 3, \text { if necessary } \\
- & \text { Delivery plan } \\
- & \text { Family planning } \\
- & \text { Risk assessment }\end{array}$ & $\begin{array}{l}\text { - Counselling according to the } \\
\text { needs of the mother and the } \\
\text { couple (domestic abuse, } \\
\text { rape, HIV and STD, FP, } \\
\text { Genetics) } \\
-\quad \text { HIV-test on site } \\
-\quad \text { Ultrasound (for accurate EDD } \\
\text { and abnormalities) } \\
\text { - Screening the social } \\
\text { circumstances where women } \\
\text { live }\end{array}$ & $\begin{array}{l}\text { These health education } \\
\text { topics to continue throughout } \\
\text { all visits but especially in the } \\
1^{\text {st }} \text { and } 2^{\text {nd }} \text { trimesters: } \\
-\quad \text { Development of normal } \\
\text { pregnancy, reproductive } \\
\text { system and conception } \\
-\quad \text { Warning signs and symptoms } \\
\text { of pregnancy related } \\
\text { problems } \\
-\quad \text { When and where to request } \\
\text { medical care } \\
-\quad \text { Nutrition, personal hygiene, } \\
\text { exercise } \\
-\quad \text { Breast care } \\
-\quad \text { Birth companion } \\
-\quad \text { Family planning and STD } \\
\text { prevention } \\
-\quad \text { Self care and own } \\
\text { responsibilities } \\
-\quad \text { Parenting } \\
-\quad \text { KMC } \\
-\quad \text { Companion for antenatal care } \\
\text { and birthing }\end{array}$ & $\begin{array}{ll}- & \text { Ability to collect data, perform } \\
\text { examinations, identify risk } \\
\text { factors and treat or refer } \\
\text { appropriately } \\
-\quad \text { History taking skills } \\
-\quad \text { Communication, motivations } \\
\text { and counselling skills } \\
-\quad \text { Knowledge and skills about: } \\
\text { pregnancy, reproductive } \\
\text { system, pregnancy related } \\
\text { diseases, guidelines and } \\
\text { protocols } \\
-\quad \text { Hb measurement } \\
-\quad \text { RPR-testing } \\
-\quad \text { Determine gestational age } \\
-\quad \text { BP measurement } \\
-\quad \text { Auscultation of heart and } \\
\text { lungs } \\
-\quad \text { Palpation of uterus and } \\
\text { measurement of SFH } \\
-\quad \text { Vaginal examination } \\
-\quad \text { Genetic counselling } \\
-\quad \text { Risk assessment skills } \\
-\quad \text { Skills to provide services for } \\
\text { youth }\end{array}$ \\
\hline SECOND & 24-28 weeks & $\begin{array}{ll}- & \text { BP/weight/urine } \\
- & \text { Hb if previous was low } \\
- & \text { Gestational age } \\
- & \text { SFH, palpation, FHB } \\
- & \text { Risk review- assessment } \\
& \text { for danger signs }\end{array}$ & $\begin{array}{ll}- & \text { Early signs of pregnancy } \\
\text { induced hypertension } \\
\text { (already weeks 20-22) } \\
-\quad \text { Twins/multiple pregnancy } \\
-\quad \text { Check blood results are } \\
\text { recorded and treatment } \\
\text { given/taken } \\
-\quad \text { Tetanus } 2 / 3 \\
-\quad \text { Foetal movements checked } \\
-\quad \text { STD management and } \\
\text { - } & \text { vulva inspection } \\
& \text { Delivery plan checked } \\
\end{array}$ & $\begin{array}{l}\text { Look at the topics in the } \\
\text { upper box; those topics } \\
\text { continue into this visit, too }\end{array}$ & \\
\hline
\end{tabular}




\begin{tabular}{|c|c|c|c|c|c|}
\hline $\begin{array}{c}\text { ANC } \\
\text { VISITS }\end{array}$ & TIME OF VISIT & $\begin{array}{l}\text { ROUTINE ANTENATAL CARE } \\
\text { SERVICES }\end{array}$ & $\begin{array}{c}\text { ADDITIONAL } \\
\text { or SPECIAL SERVICES }\end{array}$ & $\begin{array}{c}\text { CONTENT OF } \\
\text { HEALTH EDUCATION }\end{array}$ & SKILLS NEEDED \\
\hline THIRD & 32 weeks & $\begin{array}{ll}- & \text { BP/weight/urine } \\
- & \text { Gestational age } \\
- & \text { SFH, presentation, FHB } \\
- & \text { Hb test to check blood } \\
& \text { dilution } \\
- & \text { Risk review }\end{array}$ & $\begin{array}{ll}- & \text { Foetal movements } \\
- & \text { Foetal growth monitoring } \\
- & \text { Pregnancy induced } \\
& \text { hypertension / eclampsia } \\
- & \text { 3/3 tetanus } \\
- & \text { PAP smears } \\
- & \text { STD control and vaginal } \\
& \text { examination }\end{array}$ & $\begin{array}{ll}- & \text { Health education before } \\
& \text { delivery: } \\
- & \text { Preparation for birth } \\
- & \text { Labour/delivery } \\
- & \text { Pain relief and delivery } \\
& \text { positions } \\
- & \text { Birth companion } \\
- & \text { Preparations for } \\
& \text { breastfeeding } \\
- & \text { STD prevention } \\
\end{array}$ & $\begin{array}{ll}- & \text { Skills to monitor foetal } \\
\text { growth } \\
-\quad \text { Skills for PAP smears }\end{array}$ \\
\hline FOURTH & 36-38 weeks & $\begin{array}{ll}- & \text { Urine/ weight/ BP } \\
- & \mathrm{Hb} \\
- & \mathrm{SFH} \\
- & \text { Lie and presentation } \\
- & \text { Gestational age } \\
- & \text { FHB } \\
- & \text { Assessment of pelvis } \\
- & \text { Risk review } \\
\end{array}$ & $\begin{array}{ll}- & \text { STD management and } \\
& \text { vaginal examination } \\
- & \text { Delivery plan checked }\end{array}$ & $\begin{array}{ll}- & \text { Exclusive breast-feeding } \\
- & \text { Physical changes after } \\
& \text { delivery } \\
- & \text { Moods after delivery } \\
- & \text { Sexuality after delivery } \\
- & \text { Care of the newborn } \\
- & \text { Family planning and STD } \\
& \text { prevention } \\
\end{array}$ & $\begin{array}{ll}- & \text { Skills to assess the size of } \\
& \text { pelvis } \\
- & \text { Good management of high } \\
& \text { risk pregnancies } \\
-\quad & \text { Skills to make delivery plan } \\
\text { with the client }\end{array}$ \\
\hline FIFTH & 40-42 weeks & $\begin{array}{ll}- & \text { Urine/ weight/ BP } \\
- & \mathrm{Hb} \\
- & \mathrm{SFH} \\
- & \text { Position and presentation } \\
- & \text { Gestational age } \\
- & \text { FHB } \\
- & \text { Assessment of pelvis } \\
- & \text { Risk review }\end{array}$ & $\begin{array}{l}\text { - Checking that all records } \\
\text { are filled and all is done for } \\
\text { safe birth }\end{array}$ & $\begin{array}{l}\text { Any questions from the } \\
\text { client }\end{array}$ & $\begin{array}{cl}- & \text { Good skills of management } \\
& \text { of women in labour } \\
- & \text { Good understanding of } \\
& \text { labour graph } \\
- & \text { Decision-making skills } \\
- & \text { Resuscitation and correct } \\
& \text { assessment of newborn } \\
- & \text { STD management skills } \\
- & \text { Knowledge and skills for } \\
- & \text { health education } \\
- & \text { Skills to interpret CTG } \\
- & \text { Apgar scoring skills } \\
\end{array}$ \\
\hline
\end{tabular}




\begin{tabular}{|c|c|c|c|c|c|}
\hline $\begin{array}{l}\text { PNC } \\
\text { VISITS }\end{array}$ & TIME OF VISIT & $\begin{array}{l}\text { ROUTINE } \\
\text { POSTNATAL CARE }\end{array}$ & ADDITIONAL or SPECIAL & $\begin{array}{l}\text { CONTENT OF } \\
\text { HEALTH EDUCATION }\end{array}$ & SKILLS NEEDED \\
\hline 7.FIRST & $\begin{array}{l}\text { Within } 7 \text { days after } \\
\text { delivery }\end{array}$ & $\begin{array}{ll}- & \text { Episiotomy/CS wound } \\
- & \text { Bleeding and vaginal } \\
& \text { discharge } \\
- & \text { Involution of uterus } \\
- & \text { Body temperature, } \\
& \text { respiration, pulse } \\
- & \text { Hb, BP, urine } \\
- & \text { Breasts and feeding } \\
- & \text { Overall health status of } \\
& \text { mother including mental } \\
& \text { status } \\
-\quad & \text { FP } \\
-\quad & \text { Immunisation (BCG }+ \\
\text { polio) }\end{array}$ & 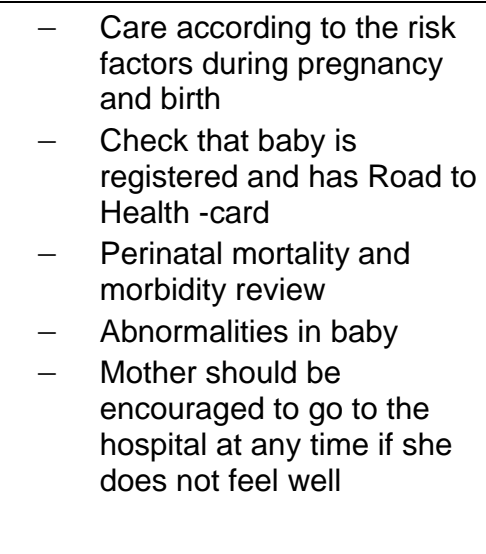 & $\begin{array}{ll}- & \text { Nutrition while breast- } \\
- & \text { feeding } \\
- & \text { Care of the new-born } \\
- & \text { Immunisations } \\
- & \text { Hygiene } \\
- & \text { Sexuality after delivery } \\
- & \text { FP } \\
- & \text { STD prevention } \\
- & \text { Birth registration }\end{array}$ & $\begin{array}{l}\text { - } \quad \text { Good knowledge of } \\
\text {-new-born care } \\
\text {-breast-feeding } \\
\text {-immunisation } \\
\text {-postnatal care } \\
-\quad \text { FP } \\
-\quad \text { Immunisation updates }\end{array}$ \\
\hline 8. SECOND & $\begin{array}{l}6 \text { weeks after } \\
\text { delivery }\end{array}$ & - As above & $\begin{array}{ll}- & \text { Maternal Morbidity and } \\
& \text { Mortality review } \\
-\quad & \text { Refer all abnormal PAP } \\
& \text { smears }\end{array}$ & - & - $\quad$ Vital registration \\
\hline
\end{tabular}




\subsection{Problems Encountered during Implementation of Interventions}

Numerous challenges occurred while implementing the new package. These included high staff turnover (many nurses emigrated to work in Europe during the study period), inadequate logistics, lack of involvement of some key stakeholders at the planning stage, and insufficient budgetary planning. Resignation and/or retirement of several master trainers and clinic staff meant that eight of the original 22 master trainers did not complete their training; some were replaced but they did not cover all the modules. By the end of the study period, only two of the six intervention clinics had at least one staff member who had covered all the training modules; two clinics had staff who had covered four modules; one clinic had staff who had received RPR training only; and one clinic did not have any staff who had covered any of the modules.

Selection of and logistical arrangements for master trainers to cascade the training to the clinics was challenging. Some of the master trainers were themselves clinic providers, and because of staff shortages at their clinics could not always leave their clinics to cascade training in the study clinics. A few of the master trainers were administrators who had little or no time to cascade the training. Although some clinic supervisors were involved as master trainers, they did not receive training on how to monitor and supervise introduction of the new package.

Although the RPR training was fully cascaded to all clinics, there were delays in delivering the RPR kits because of inadequate involvement of hospital laboratory personnel the planning stage and because no budget had been set aside for the extra RPR kits required. In addition, the RPR training did not include ordering for kits and the clinic staff initially did not know what to order and in what quantity. Transport to take specimens to the labs for quality checks was initially a challenge, but the District management provided additional funding to cover transportation before the endline survey was conducted.

\section{Study Methodology}

\subsection{Study design}

This study used a quasi-experimental control group design, with health facilities offering ANC services (hospitals and clinics) as the sampling units. The study population was all clients seeking antenatal care services on the day of the research team's visit. The study was designed to have two phases; the first to assess the effect of introducing the new package of antenatal services on the performance and quality of care at the clinics, and the second phase was to be undertaken if the interventions had been implemented successfully and there were clear improvements in quality of care. Due to mixed results and challenges in implementing the interventions, the second phase of the study was not conducted.

\section{Diagram of the Study Design}

$\begin{array}{llll}\text { Experimental clinics } & \mathrm{O}_{1} & \mathrm{X}_{1-4} & \mathrm{O}_{3} \\ \text { Comparison clinics } & \mathrm{O}_{2} & & \mathrm{O}_{4}\end{array}$


$\mathbf{O}_{1}$, and $\mathbf{O}_{2}$ were pre-intervention measurements of quality of care variables.

$\mathbf{O}_{3}$ and $\mathbf{O}_{4}$ were post intervention measurement of quality of care variables

$\mathbf{X}_{\mathbf{1}}$ : Staff training to improve provider competence

$\mathbf{X}_{2}$ : Ensuring availability of a minimum level of equipment and supplies required for providing routine ANC and post-natal services, STIs, FP and on-site syphilis screening

$\mathbf{X}_{\mathbf{3}}$ : Increasing the availability of appropriate IEC materials, guidelines and protocols

$\mathbf{X}_{4}$ : Integrating STI and HIV prevention counselling and STI management into routine ANC service provision; introducing on-site syphilis screening; and goal directed visits

\subsection{Sampling}

The study was implemented in two districts that were purposively selected at the request of the Provincial DOH. Zululand district (DC 24) was selected as the district in which to introduce the intervention, and Umzinyathi district (DC 26) was chosen as the comparison district because it is neighbouring to Zululand and has similar socio-economic, cultural and health services characteristics. To be able to assess the inclusion of VCT services for ANC clients, hospitals were selected for the study only if they currently offered VCT services. Two hospitals were selected in each district.

All clinics referring clients to these hospitals were included in the sample. However, those that saw less than 90 new ANC clients in the previous three-month period had to be excluded because it would not have been possible to collect a large enough sample from these clinics. The remaining clinics were then grouped into three categories based on the volume of clients served in a three-month period:

Low volume $\quad 90-115$

Medium volume $\quad 116-170$

High volume $\quad 171+$

From the group of clinics referring to each hospital, one clinic was randomly chosen to represent each of these categories, giving three clinics per hospital, i.e. a total of twelve study clinics, six intervention clinics in DC 24 and six comparison clinics in DC 26.

An inventory was completed for each clinic and all staff providing ANC services were interviewed. In addition, observation of client-provider interactions and exit interviews with samples of consenting new and repeat clients accessing ANC services on the date of the visit were conducted, with a target of six first and six repeat clients for each clinic. Table 4.1 describes the sample sizes achieved.

Table 4.1 Sample Sizes

\begin{tabular}{|c|c|c|c|c|c|c|c|c|c|c|}
\hline & \multicolumn{4}{|c|}{ Baseline } & \multicolumn{4}{|c|}{ Endline } & \multicolumn{2}{|c|}{ Total } \\
\hline & \multicolumn{2}{|c|}{ Intervention } & \multicolumn{2}{|c|}{ Comparison } & \multicolumn{2}{|c|}{ Intervention } & \multicolumn{2}{|c|}{ Comparison } & Base & End \\
\hline Provider Interviews & \multicolumn{2}{|c|}{14} & \multicolumn{2}{|c|}{29} & \multicolumn{2}{|c|}{19} & \multicolumn{2}{|c|}{34} & 43 & 53 \\
\hline \multirow[t]{2}{*}{ Clinic Inventory } & \multicolumn{2}{|c|}{6} & \multicolumn{2}{|c|}{6} & \multicolumn{2}{|c|}{6} & \multicolumn{2}{|c|}{6} & 12 & 12 \\
\hline & Ist & rep & 1st & rep & $1^{\text {st }}$ & rep & 1st & rep & & \\
\hline $\begin{array}{l}\text { Client-provider } \\
\text { observations }\end{array}$ & 60 & 61 & 65 & 63 & 53 & 66 & 49 & 85 & 249 & 253 \\
\hline Exit Interviews & 58 & 57 & 64 & 62 & 52 & 67 & 49 & 85 & 241 & 253 \\
\hline
\end{tabular}

Feasibility of introducing a comprehensive integrated package of antenatal care services in rural public 9 clinics in South Africa 


\subsection{Data collection}

Four instruments were used to collect data from each sample clinic:

1. Clinic inventory and record review

2. Provider questionnaire

3. Observation guide for interaction between ANC clients and service providers

4. Exit interview questionnaire for observed ANC clients.

Each study clinic was visited for two or three days (both at baseline and endline) when ANC services are offered ${ }^{3}$. Through interviews with the clinic nurse in-charge, observations and a review of clinic records, the inventory collected information regarding a clinic's infrastructure, staffing, logistics for drugs and supplies, management and supervision, type of services provided, equipment, contraceptives and essential drugs supply. The provider questionnaire measured training, qualifications, knowledge, supervision and job satisfaction from all staff providing ANC services on the day of visit. All consenting clients and staff were observed during their interaction to measure the type and quality of services received by the client. All consenting clients who had been observed were then asked for an interview to get information on their socio-demographic characteristics and satisfaction with clinic services. Apart from eight exit interviews at baseline that were not completed due to the client's referral for emergency care or the arrival of transport to take the client home, all clients and providers consented to and completed the interviews.

\section{Socio-demographic Characteristics of respondents}

\subsection{Providers}

The majority of providers interviewed were females (39 / 43 at baseline and 42 / 49 at endline) and registered nurse midwifes. The proportion of registered midwifes and midwifes was higher in the intervention clinics (12 / 14 baseline and 10 / 19 endline) than in the comparison clinics (15 / 29 baseline and 11 / 30 endline), because a substantial number of providers in the comparison site were student nurse midwifes ( 8 at baseline and 5 at endline).

Excluding student nurses from the analysis, the number of years worked by nurses at the facility ranged from 1 to 29 years, with the majority (31\% baseline and 51\% endline) having worked at the clinic for one year or less. There was great variation in the number of years since the provider had graduated (1-41 years), with a median of 8 years both at baseline and endline (see Appendix 1 for more detail).

\subsection{Clients}

The majority of the clients were young, with about one-quarter being adolescents and a significant proportion being first time mothers. Educational achievement was quite high overall, although significantly higher among intervention clinic clients than comparison clinic clients. The majority were unmarried and not living with a partner, being housewives or unemployed. It is important to note an increase in the proportion of students in the endline survey, in both the intervention and comparison clinics; it is unclear why this should be.

There was no significant difference between the intervention and comparison clinic clients in their sexual behaviour. Almost all (99\%) had a regular partner, both at baseline and endline.

$3 \quad$ See Appendix 4 for a list of persons responsible for data collection. 
The majority (92\% intervention and 95\% comparison) had had sex with their regular partner in the past six months, although this proportion reduced slightly at endline. For those few who had not had sex with their partners, the majority were in their third trimester, implying that sex with a regular partner becomes infrequent later in pregnancy. Condom use was very low among these clients - of those having sex in the past six months, 10 percent at baseline and 15 percent at endline had ever used a condom. Two percent reported having had sex with a non-regular partner in the past six months (see Appendix 1 for more detail).

Although the first ANC visit should take place between 4 and 20 weeks gestation, about half of clients' first access services after 20 weeks, and less than 10 percent access services during the first trimester. There was no significant difference in gestational age at first visit between the intervention and comparison clinics.

\section{Preparedness of Facilities}

\subsection{Facility Infrastructure}

The study sought to strengthen the availability and functioning of the basic infrastructure necessary for offering quality services, even though the DOH could not improve some items (such as electricity supply and number of consultation rooms) within the period of the intervention. Of the five infrastructure items identified as essential for quality services, at baseline all clinics had a protected client waiting area, toilets, and a working phone or short wave radio, and, apart from one intervention clinic, all had electricity supply (although in three comparison facilities electricity is interrupted once or twice a month). Running tap water was not available in two intervention clinics, but the DOH provided this by the endline survey. The number of consultation rooms per facility ranged from 2 to 11 , and although high volume facilities were more likely to have a higher number of rooms, two high volume clinics (one intervention and one comparison) had only three consultation rooms.

\subsection{Staffing}

All intervention and comparison clinics had staff qualified to provide ANC, FP, STI and HIV/AIDS counselling ${ }^{4}$. The number of service providers per clinic (excluding community health workers (CHWs) and AIDS counsellors) ranged from 3 to 11 at baseline and 2 to 15 at endline. On average, both at baseline and endline, the comparison clinics (6.3 baseline, 8.0 at endline) had more providers than the intervention clinics (4.8 at baseline, 4.2 at endline).

The average number of nurses with midwifery qualification decreased over time in the intervention clinics but increased in the comparison clinics due to staff movement. Only one clinic had AIDS counsellors at baseline but at endline all 6 intervention clinics had at least one AIDS counsellor and the comparison clinics between 2 to 9; this increase across all clinics reflects the nationwide programme to roll out VCT and PMTCT services.

\subsection{Supervision and Management}

The level of supervision and monitoring provided to clinics was below standard, particularly in the intervention clinics. At baseline, less than half (19/43) of the providers reported

\footnotetext{
$4 \quad$ The only exceptions were one intervention clinic at endline that did not have staff qualified to provide
} ANC services, and one comparison clinic that did not have staff with FP training. 
receiving a supervisory visit in the previous six months, although providers in the intervention clinics $(8 / 14)$ were more likely to have received a supervisory visit than those in the comparison clinics (11/29). At endline, the proportion had reduced significantly in the intervention clinics (4/19), while increasing significantly in the comparison clinics (24/30). It is not clear why this happened, but changes in personnel and compensation are often the causes of such shifts.

For those providers reporting having received supervision, both at baseline and endline, the supervision was described as supportive, with supervisors observing providers at work and discussing relevant issues. When visiting clinics, supervisors were reported to perform a wide variety of tasks: discussing problems, checking registers, discussing policy or administrative issues, discussing protocols, holding staff meetings, observing individual staff providing services, checking the cleanliness of the facility, delivering medications, holding workshops, and checking the functioning of and replacing broken equipment.

There was some improvement in monitoring the quality of care provided to clients over time through use of supervisory checklists, periodic audit of medical records and service registers, 'Quality Assurance' or 'COPE' committees, and supervision by Provincial or District Health Management Teams. Formal staff meetings to discuss facility management and administrative issues are held regularly, usually monthly, and an official record is kept. Most clinics seek to involve the community through community representatives' participation in routine clinic management meetings. In addition, all clinics have a system for determining clients' opinions about the health facility and/or services, with eleven clinics use a suggestion box and other clinics getting views through interviews with groups of clients and/or confidential interviews with individual clients.

\subsection{Availability of IEC Materials, Protocols and Guidelines}

The DOH has developed various guidelines and protocols to guide and support maternal and reproductive health service provision. In addition, there are several IEC materials that all clinics are expected to have as reference materials and visual aids for teaching about different services and leaflets or information booklets for clients to take home for reference. As Tables 6.1 and 6.2 indicate, there was a significant improvement in the number of guidelines available in the intervention clinics only, and some (non-significant) decreases in availability of IEC materials in the intervention clinics and increases in the comparison clinics. Even in clinics where these guidelines and protocols were available, in most cases they were not accessible because they were not placed in consultation rooms. 
Table 6.1 Numbers of Clinics Having Guidelines and Protocols

\begin{tabular}{|l|c|c|c|c|}
\hline & \multicolumn{2}{|c|}{ Intervention } & \multicolumn{2}{c|}{ Comparison } \\
\hline & $\begin{array}{c}\text { Baseline } \\
(\mathrm{n}=6)\end{array}$ & $\begin{array}{c}\text { Endline } \\
(\mathrm{n}=6)\end{array}$ & $\begin{array}{c}\text { Baseline } \\
(\mathrm{n}=6)\end{array}$ & $\begin{array}{c}\text { Endline } \\
(\mathrm{n}=6)\end{array}$ \\
\hline Reproductive Health & 3 & 5 & 5 & 6 \\
\hline Maternal health care & 5 & 5 & 6 & 6 \\
\hline Teaching aid for ANC & 4 & 5 & 3 & 2 \\
\hline Guidelines for diagnosing HIV & 2 & 4 & 4 & 4 \\
\hline Informed consent for protocol for HIVIAIDS & 1 & 5 & 4 & 5 \\
\hline Written protocol for referral for HIVIAIDS & 2 & 5 & 3 & 4 \\
\hline Confidentiality protocol for STI clients & 1 & 5 & 2 & 2 \\
\hline Informed consent protocol for STI testing & 0 & 4 & 1 & 2 \\
\hline Guidelines for syndromic management of STIS & 6 & 6 & 6 & 6 \\
\hline Guidelines for clinical diagnosis of STI & 6 & 6 & 6 & 6 \\
\hline Mean number of guidelines reported and observed & $\mathbf{5 . 3 3}$ & $\mathbf{8 . 5 0}$ & $\mathbf{6 . 6 7}$ & $\mathbf{7 . 1 6}$ \\
\hline Mean number observed in ANC rooms & $\mathbf{3 . 5}$ & $\mathbf{4 . 1 7}$ & $\mathbf{2 . 0 0}$ & $\mathbf{4 . 8 3}$ \\
\hline
\end{tabular}

Table 6.2 Numbers of Clinics Having IEC Materials

\begin{tabular}{|l|c|c|c|c|}
\hline & \multicolumn{2}{|c|}{ Intervention } & \multicolumn{2}{c|}{ Comparison } \\
\hline & $\begin{array}{c}\text { Baseline } \\
(\mathrm{n}=6)\end{array}$ & $\begin{array}{c}\text { Endline } \\
(\mathrm{n}=6)\end{array}$ & $\begin{array}{c}\text { Baseline } \\
(\mathrm{n}=6)\end{array}$ & $\begin{array}{c}\text { Endline } \\
(\mathrm{n}=6)\end{array}$ \\
\hline Visual aids for FP methods & 5 & 2 & 5 & 6 \\
\hline Visual aids for postpartum FP care & 5 & 5 & 3 & 4 \\
\hline Visual aid, pregnancy danger signs & 2 & 3 & 1 & 4 \\
\hline FP posters & 6 & 3 & 5 & 5 \\
\hline FP pamphlets and booklets & 4 & 3 & 3 & 3 \\
\hline Postnatal pamphlets, booklets & 2 & 3 & 0 & 2 \\
\hline STI visual aids & 4 & 5 & 3 & 6 \\
\hline HIVIAIDS visual aids & 5 & 3 & 1 & 5 \\
\hline Condom demonstration model & 4 & 1 & 1 & 6 \\
\hline STI pamphlets, booklets & 5 & 3 & 2 & 4 \\
\hline HIVIAIDS pamphlets, booklets & 4 & 3 & 2 & 6 \\
\hline
\end{tabular}

\subsection{Availability of Equipment and Supplies}

\subsubsection{Availability and Functioning of Equipment}

Out of the 20 types of essential equipment that a clinic must have to offer quality ANC and postnatal services, no single clinic had all the required equipment in working order. As indicated in Table 6.3, however, by the endline survey almost all the intervention and comparison clinics had most of the equipment in working order. 
Table 6.3 Numbers of clinics having equipment in working order

\begin{tabular}{|l|c|c|c|c|}
\hline & \multicolumn{2}{|c|}{ Intervention } & \multicolumn{2}{c|}{ Comparison } \\
\hline & $\begin{array}{c}\text { Baseline } \\
(\mathbf{n}=6)\end{array}$ & $\begin{array}{c}\text { Endline } \\
(\mathrm{n}=6)\end{array}$ & $\begin{array}{c}\text { Baseline } \\
(\mathrm{n}=6)\end{array}$ & $\begin{array}{c}\text { Endline } \\
(\mathrm{n}=6)\end{array}$ \\
\hline Examination couch & 4 & 6 & 6 & 6 \\
\hline Examination lights & 2 & 3 & 4 & 5 \\
\hline Adult weighing scale & 6 & 6 & 6 & 6 \\
\hline Infant weighing scale & 5 & 6 & 6 & 6 \\
\hline BP machine & 6 & 6 & 6 & 6 \\
\hline Stethoscope & 6 & 6 & 6 & 6 \\
\hline Foetal stethoscope & 6 & 6 & 6 & 6 \\
\hline Fridge & 6 & 6 & 6 & 6 \\
\hline Cooler boxes & 6 & 6 & 6 & 5 \\
\hline Sharp disposable & 6 & 6 & 6 & 6 \\
\hline Swabs container & 4 & 5 & 0 & 3 \\
\hline Swabs & 2 & 6 & 4 & 3 \\
\hline Urine strips & 5 & 6 & 6 & 5 \\
\hline Needles and syringes & 6 & 6 & 5 & 6 \\
\hline Vacutainer & 4 & 5 & 2 & 2 \\
\hline Disposal gloves & 6 & 6 & 6 & 6 \\
\hline Surgical disinfectant & 4 & 6 & 4 & 6 \\
\hline Thermometer & 5 & 6 & 6 & 6 \\
\hline Storage area/cupboard & 5 & 6 & 5 & 5 \\
\hline Oxygen equipment & 1 & 6 & 5 & 5 \\
\hline
\end{tabular}

\subsubsection{Availability of Essential Drugs, Vaccines and Supplies}

To provide quality ANC services according to national guidelines, a clinic should have all the required drugs and vaccines available on-site. As Table 6.4 indicates, there was an increase in availability of essential ANC and postnatal care drugs and vaccines in both intervention and comparison clinics.

Out of the six STI drugs recommended for syndromic treatment, erythromycin, ciprobay and doxycyclene were available in all the clinics both at baseline and at endline. Flagyl was outof-stock in three comparison clinics at baseline and two intervention clinics at endline; metronidazole was out-of-stock in two intervention and one comparison clinics at baseline and in two comparison clinics at endline; benzathin penicillin was out-of-stock in one intervention clinic at endline only. 
Table 6.4 Numbers of clinics having essential supplies

\begin{tabular}{|l|c|c|c|c|}
\hline & \multicolumn{2}{|c|}{ Intervention } & \multicolumn{2}{c|}{ Comparison } \\
\hline & $\begin{array}{c}\text { Baseline } \\
(\mathrm{n}=6)\end{array}$ & $\begin{array}{c}\text { Endline } \\
(\mathrm{n}=6)\end{array}$ & $\begin{array}{c}\text { Baseline } \\
(\mathrm{n}=6)\end{array}$ & $\begin{array}{c}\text { Endline } \\
(\mathrm{n}=6)\end{array}$ \\
\hline Immunization cards & 4 & 6 & 6 & 5 \\
\hline ANC clients' card & 5 & 6 & 6 & 6 \\
\hline Folic acid & 4 & 6 & 6 & 6 \\
\hline Ferrous sulphate & 4 & 6 & 6 & 6 \\
\hline Tetanus toxoid injection & 4 & 6 & 3 & 6 \\
\hline Combout & 1 & 1 & 3 & 3 \\
\hline BCG & 5 & 6 & 4 & 6 \\
\hline Polio drops & 4 & 6 & 5 & 6 \\
\hline Measles vaccine & 5 & 6 & 5 & 4 \\
\hline DPT & 5 & 6 & 5 & 6 \\
\hline HIP Vaccine & 3 & 6 & 4 & 5 \\
\hline Hepatitis B vaccine & 4 & 6 & 5 & 6 \\
\hline DT vaccine & 4 & 6 & 4 & 6 \\
\hline Ringer lactate solution & 0 & 5 & 5 & 4 \\
\hline Magnesium sulphate & 0 & 5 & 3 & 2 \\
\hline Lexoprenaline & 0 & 4 & 3 & 2 \\
\hline
\end{tabular}

\subsubsection{Availability of Contraceptives}

As Table 6.5 indicates, the majority of clinics had sufficient stock of most contraceptive methods. Intra-uterine contraceptive devices (IUCD), Norplant ${ }^{\circledR}$ implants, spermicides, diaphragms, and female condoms are not offered in all clinics and so are not included in this table.

Apart from one intervention clinic that was re-supplied with a fixed amount of contraceptives, all clinics determine the amount of each method they receive. Most clinics (4 intervention and 3 comparison) order differing amounts based on calculations of prior utilization and expected future activity. Two clinics ( 1 intervention and 1 comparison) order sufficient to bring their stock to certain levels, and one comparison clinic orders the same quantity each time. Clinics do not always receive the amount they order, but there was a marked improvement in the intervention clinics. As the intervention did not focus on improving logistics, it is not clear whether this improvement can be attributed to the intervention.

Clinics have made condoms easily accessible to clients by placing them in different locations within and close to the clinic, but none have placed condoms in a locality (such as toilets) where privacy is guaranteed. Nine placed condoms in the waiting room, 10 in the consultation rooms, 4 with security guards, 4 outside the clinic gate, and 6 in other locations (e.g. shops, phone outlets and schools, at reception, in clinic corridors). Seven clinics reported storing condoms in dispensers and 10 reported storing them in boxes. Only two clinics reported a condom stock-out in the past three months. At baseline and endline, all dispensers and boxes were stocked with condoms, apart from in two comparison clinics. 
Table 6.5 Numbers of Clinics Having Stock-outs in Various Contraceptives

\begin{tabular}{|l|cc|cc|}
\hline & \multicolumn{2}{|c|}{ Intervention } & \multicolumn{2}{c|}{ Comparison } \\
\hline & $\begin{array}{c}\text { Baseline } \\
(\mathrm{n}=6)\end{array}$ & $\begin{array}{c}\text { Endline } \\
(\mathrm{n}=6)\end{array}$ & $\begin{array}{c}\text { Baseline } \\
(\mathrm{n}=6)\end{array}$ & $\begin{array}{c}\text { Endline } \\
(\mathrm{n}=6)\end{array}$ \\
\hline Depo Provera & 0 & 0 & 0 & 0 \\
\hline Nuristerate & 0 & 0 & 0 & 0 \\
\hline FP triphasul & 0 & 0 & 0 & 0 \\
\hline FP Nordette & 1 & 0 & 0 & 0 \\
\hline Microval & 0 & 0 & 1 & 0 \\
\hline Ovral & 0 & 0 & 1 & 2 \\
\hline Pre-packed EC & 5 & 6 & 6 & 6 \\
\hline Male Condoms & 1 & 0 & 1 & 0 \\
\hline \multicolumn{7}{|l|}{} & 0 & 3 & 1 & 3 \\
\hline Clinic Receives Correct Amount of Contraceptives Ordered \\
\hline Always & 0 & 2 & 3 & 1 \\
\hline Sometimes & 2 & 1 & 2 & 2 \\
\hline Almost never & 4 & \multicolumn{5}{l}{} \\
\hline
\end{tabular}

\subsection{Summary Measures of Clinic Preparedness}

A mean summary score for all 'preparedness' items discussed above was calculated for each group of clinics, and compared statistically (see table 6.6). An overall improvement was found in both groups preparedness, but this was statistically significant only in the intervention clinics. It can be concluded that the intervention was successful in strengthening the intervention clinics' preparedness to offer the new ANC package, although several weaknesses remained, as indicated by the mean score of 58.5 out of a possible 71 .

Table 6.6 Mean Preparedness Scores by Site

\begin{tabular}{|l|c|c|c|c|}
\hline & \multicolumn{2}{|c|}{ Baseline } & \multicolumn{2}{c|}{ Endline } \\
\hline & $\begin{array}{c}\text { Intervention } \\
(\mathbf{N}=6)\end{array}$ & $\begin{array}{c}\text { Comparison } \\
(\mathbf{N}=6)\end{array}$ & $\begin{array}{c}\text { Intervention } \\
(\mathbf{N}=6)\end{array}$ & $\begin{array}{c}\text { Comparison } \\
(\mathbf{N}=6)\end{array}$ \\
\hline Guidelines \& protocols (score 0-10) & 4.83 & 6.50 & 8.17 & 7.17 \\
\hline IEC materials (Score 0-11) & 7.17 & 4.33 & 6.00 & $8.83^{* *}$ \\
\hline Equipment (Score 0-20) & 14.83 & 17.00 & 19.17 & 16.67 \\
\hline Supplies (Score 0-16) & 7.67 & 9.67 & 13.20 & $9.67^{*}$ \\
\hline Contraceptive methods (Score 0-8) & 7.00 & 7.17 & 6.83 & 7.33 \\
\hline STI drugs (Score 0-6) & 5.67 & 5.33 & 5.50 & 5.67 \\
\hline Total (0-71) & $\mathbf{4 7 . 1 7}$ & $\mathbf{5 0 . 0 0}$ & $\mathbf{5 8 . 5 0 ^ { * }}$ & $\mathbf{5 5 . 3 3}$ \\
\hline
\end{tabular}




\section{Quality of services ${ }^{5}$}

\subsection{Availability of Services}

ANC, $\mathrm{FP}^{6}$, child immunization and STI services were available in all the clinics at least once a week. At baseline, four clinics provided ANC services from Monday to Friday (as per DOH recommendations), six provided ANC once a week, and two provided ANC twice a week, and these schedules remained by endline $e^{7}$. Due to staff shortages and other challenges (such as water shortages), services were not always available on the specified days, and as staff providing ANC services are also responsible for other services, in all clinics, at baseline and endline surveys, ANC clients had opportunities to access FP (including postpartum FP counselling), STI and VCT services during their ANC visits.

All clinics provide progesterone-only pills, combined oral pills, 3 and 2 monthly injectables, and male condoms to their clients. Only one intervention clinic reported offering counselling on natural family planning. Two intervention clinics and one comparison clinic reported providing emergency contraception, while female condoms, spermicides, diaphragm, IUCD, and Norplant ${ }^{\circledR}$ implants were not provided in any clinics.

STI diagnosis and treatment for women coming in specifically with STI symptoms, or for those who were found to be symptomatic during ANC visits, were offered during all working days $^{8}$. All facilities offered STI services within the general outpatient clinic.

Syphilis screening was a routine service for ANC clients in all clinics and at baseline. All clinics collected blood from the ANC clients and transported it to the referral laboratory for testing. Most of the comparison clinics did not report serious problems with transportation of specimens, but three intervention clinics reported delays in transporting and getting results back. In most cases, these clinics sent specimens to the hospitals in batches once a month, when the providers went to the hospital for in-service training. Through introduction of the on-site syphilis screening through RPR testing, five of the six intervention clinics were offering same-day testing at the endline survey.

There was an increase in the number of clinics providing on-site VCT services from 2 to 5 in the intervention district and 3 to 5 in the comparison district; the remaining clinics referred clients requiring VCT to their referral hospital. Most clinics providing VCT services did not have contact lists for, or partnership with, HIV positive support groups.

\subsection{Staff Training}

The majority of providers, in both intervention and comparison clinics, reported having been trained in many aspects of ANC, FP and STI diagnosis and treatment as part of their basic training. However, as Table 7.1 indicates, less than $20 \%$ of the providers in all clinics had received training in PMTCT, exclusive breastfeeding, medical management of HIV positive patients, and ART in their basic training. While the proportion of providers who had received

\footnotetext{
$5 \quad$ Key indicators are provided in tables. For information on other indicators not included in the tables in the text, see Appendix 3.

$6 \quad$ One intervention clinic provided FP only twice a week.

$7 \quad$ One clinic offering ANC once a week switched to a daily schedule by endline.

$8 \quad$ One comparison clinic offered STI services only three days a week.
}

Feasibility of introducing a comprehensive integrated package of antenatal care services in rural public clinics in South Africa 
these types of training in their basic training increased in the comparison clinics over time, it declined in the intervention clinics, mainly due to staff turnover.

\section{Table 7.1 Number of staff receiving training as part of basic training}

\begin{tabular}{|l|cc|cc|}
\hline & \multicolumn{2}{|c|}{ Intervention } & \multicolumn{2}{c|}{ Comparison } \\
\hline FP Counselling & $\begin{array}{c}\text { Baseline } \\
(\mathrm{n}=\mathbf{1 4})\end{array}$ & $\begin{array}{c}\text { Endline } \\
(\mathrm{n}=\mathbf{1 9})\end{array}$ & $\begin{array}{c}\text { Baseline } \\
(\mathrm{n}=\mathbf{2 9})\end{array}$ & $\begin{array}{c}\text { Endline } \\
(\mathrm{n}=\mathbf{3 0})\end{array}$ \\
\hline Providing contraceptive technology & 9 & 9 & 17 & 23 \\
\hline ANC & 7 & 9 & 17 & 20 \\
\hline Health education & 13 & 10 & 23 & 18 \\
\hline Management of pregnancy risks & 13 & 10 & 21 & 25 \\
\hline Management of normal delivery & 11 & 8 & 16 & 19 \\
\hline Postnatal care & 1 & 11 & 15 & 17 \\
\hline STI syndromic management & 13 & 12 & 15 & 20 \\
\hline Clinical diagnosis of STIs & 10 & 10 & 18 & 20 \\
\hline Counselling on STI prevention & 9 & 9 & 19 & 20 \\
\hline PMTCT & 10 & 8 & 21 & 21 \\
\hline Counselling on HIV prevention & 5 & 4 & 9 & 17 \\
\hline Counselling/social support for HIV positive & 8 & 2 & 10 & 17 \\
\hline Antiretroviral drug therapy & 2 & 2 & 3 & 9 \\
\hline
\end{tabular}

\subsection{Provision of routine antenatal care services}

\subsubsection{Interpersonal relations and privacy}

Three behaviours were assessed to measure interpersonal relations: whether the provider greeted the client; introduced herself/himself to the client; and encouraged or gave opportunity to the client to ask questions. At baseline and endline, providers greeted over 90 percent of the clients. Providers in the intervention clinics (38\%) were significantly $(p<.01)$ less likely than those from comparison clinics (58\%) to introduce themselves at baseline, but by endline those in the intervention clinics had significantly improved and performed slightly better than the comparison clinics (72\% intervention, 63\% comparison). Most providers did not encourage clients to ask questions ( $26-45 \%$ of consultations), and at both baseline and endline, clients at intervention clinics were significantly less likely than those from comparison clinics to ask questions or be encouraged to ask questions.

Privacy was not a problem in any clinics, with the vast majority (96\% baseline and $92 \%$ endline) of clients receiving their consultation in a confidential environment where visual and auditory privacy was observed, although clients from the intervention clinics (88\%) were significantly $(\mathrm{p}<.05)$ less likely than those attending comparison $(96 \%)$ clinics to have privacy $^{9}$.

\footnotetext{
9 It is important to note, however, that this difference is attributable to one high volume intervention
} clinic that was highly congested and had only two ANC consultation rooms. 
A mean summary score calculated for these four items shows that the intervention clinics achieved a significantly ( $\mathrm{p}>$.001) lower mean score (2.42) than the comparison clinics (2.95) at baseline. At endline, however, although the comparison clinics still had a higher mean score, this difference was not significant, suggesting some improvement had occurred in the intervention clinics.

\subsubsection{Assessment of age and pregnancy status}

All providers performed well, and with no change over time, in assessing first visit client's age, number of previous pregnancies and information to help determine the gestational age. Providers assessed between 83 - 100 percent of first visit clients on these factors; there was no significant difference between providers in any clinics or over time.

\subsubsection{Risk assessment and counselling on pregnancy danger signs}

Consultations with first visit clients who had had a previous pregnancy ( $n=61$ baseline, $n=$ 43 endline) were assessed in terms of whether the provider enquired about experiences with previous pregnancies: any stillbirths, any infant died during or before 1 week after birth, any bleeding and any assisted delivery in the previous pregnancies. Less than 50 percent of clients were assessed for these risk factors in the intervention and comparison clinics, and at baseline and endline.

First visit clients were significantly more likely than repeat clients to be assessed for and receive counselling on pregnancy danger signs. Although the proportion of first visit clients who were assessed for at least one pregnancy danger sign increased (non-significantly) over time in both intervention and comparison clinics, the mean number of danger signs assessed for first visit clients reduced significantly between baseline and endline in intervention clinics, while the number for the comparison clinics did not change significantly (see table 7.2). Large and significant declines in the proportion of first visit clients assessed for current medication, abnormal vaginal discharge and bleeding were found; whether this was a result of the training received for the content for a first visit under the new regime is not known, but should be checked. In both groups the mean number of danger signs for which a woman was counselled remained unacceptably low, with women, on average, being counselled on less than two out a possible eight signs. 
Table 7.2 Proportions of first visit clients assessed for and provided information and counselling on pregnancy danger signs

\begin{tabular}{|c|c|c|c|c|}
\hline & \multicolumn{2}{|c|}{ Intervention } & \multicolumn{2}{|c|}{ Comparison } \\
\hline & $\begin{array}{c}\text { Baseline } \\
(n=58)\end{array}$ & $\begin{array}{c}\text { Endline } \\
(n=64)\end{array}$ & $\begin{array}{c}\text { Baseline } \\
(n=52)\end{array}$ & $\begin{array}{c}\text { Endline } \\
(n=49)\end{array}$ \\
\hline \multicolumn{5}{|c|}{ Percent Assessed for Current Pregnancy Danger Signs } \\
\hline Felt baby move & 72 & 60 & 75 & 84 \\
\hline Any problem thinks related to pregnancy & 68 & 50 & 70 & $90^{*}$ \\
\hline Medicine currently taking & 59 & $37^{*}$ & 58 & 41 \\
\hline Abnormal vaginal discharge & 48 & $12^{\star \star \star}$ & 31 & $53^{*}$ \\
\hline Bleeding & 38 & $8^{\star \star \star}$ & 8 & 12 \\
\hline Assessed for at least one danger sign & 77 & 92 & 85 & 98 \\
\hline Mean number of danger signs assessed & 2.81 & $1.67^{\star \star \star}$ & 2.43 & 2.79 \\
\hline Mean score high client load & 3.95 & 1.55 & 2.50 & 2.76 \\
\hline Mean score medium client & 3.40 & 1.82 & 2.22 & 2.75 \\
\hline Mean score low client & 1.46 & 1.67 & 2.56 & 2.92 \\
\hline \multicolumn{5}{|c|}{ Percent Provided Counselling on Pregnancy Danger Signs } \\
\hline Vaginal bleeding & 36 & 31 & 22 & 41 \\
\hline Severe headache or blurred vision & 34 & 25 & 5 & $37^{\star \star \star}$ \\
\hline Swollen hands and face & 28 & 27 & 47 & 20 ** \\
\hline Excessive tiredness and breathlessness & 19 & 10 & 2 & $18^{\star \star}$ \\
\hline Fever & 19 & 14 & 0 & $16^{\star \star \star}$ \\
\hline Sudden gush of water in the vagina & 16 & 25 & 22 & $43^{*}$ \\
\hline Foul smelling discharge postpartum & 3 & 12 & 13 & 4 \\
\hline Fever \& lower abdominal pain in postpartum & 3 & 4 & 2 & 2 \\
\hline Mean number of danger signs counselled & 1.55 & 1.47 & 1.09 & $1.82^{*}$ \\
\hline Mean score high client load & 2.57 & 1.64 & 1.56 & 1.71 \\
\hline Mean score medium client & 1.47 & 1.18 & .95 & 1.55 \\
\hline Mean score low client & .71 & 1.57 & 0.88 & 2.42 \\
\hline
\end{tabular}

\subsubsection{Physical assessments and blood tests}

All clinics performed quite well in conducting routine checks for weight and height, blood pressure, urine analysis and palpation of the abdomen; over 98 percent of all first visit clients received all of these services, at baseline and endline. Between 89 percent and 95 percent of clients had their foetal heartbeat checked. There was no significant change over time both in the intervention and comparison clinics.

Blood for Hb testing was taken for over 90 percent of the first visit clients both at baseline and endline, and all clients tested received their results the same day. Between 88 percent and 
92 percent of first visit clients had blood drawn for syphilis testing; there was no significant difference between the intervention and comparison clinics at baseline and endline. Due to inadequacies in record keeping, it is difficult to ascertain the proportion of clients who received their results. At endline, only 58 percent of first visit clients attending intervention clinics had syphilis screening done on site and received their results on the same day. This was largely because one high-volume clinic had not started conducting the RPR on-site screening at the time of data collection.

The intervention clinics started conducting the RPR test at different times; one clinic started in January 2003, another in February, a third in March; two in April; and one high volume clinic did not start until August 2003. In addition, onsite testing was not performed consistently every month in some of the clinics. Records from January to October 2003 from the five active clinics indicate that, of the 848 clients that had syphilis screening conducted onsite, only 359 (42\%) had complete data indicating clinic results and laboratory confirmatory/quality check results. Out of these, the clinics identified 40 (11\%) as reactive, while the laboratory results confirmed only 28 (7.8\%) as reactive - although the differences were only found among women attending two of these clinics. Syphilis sero-prevalence varied from 5.6 percent to 9.7 percent across the clinics.

\subsubsection{Tetanus immunization and Folic Acid/ Ferrous Sulphate Supplements}

The vast majority of first visit clients (92 - 95 \%) at baseline were given folic acid and iron supplements, but these proportions reduced slightly at endline (87-92\%). Approximately two-thirds of first visit clients (68 - 72\%) were assessed for ATT at baseline, but these figures decreased (albeit non-significantly) at endline (48 - 59\%). About two thirds (66 $72 \%$ ) of all first visit clients were given tetanus toxoid injections at baseline, and this increased to over three-quarters $(87-78 \%)$ at endline, significantly $(\mathrm{P}<.05)$ in the intervention clinics.

Clients accessing services from intervention clinics were more likely at baseline to be provided with an explanation about specimens taken, medications given, and how to take them (see table 7.3), but these proportions reduced substantially over time, particularly in the intervention clinics. First visit clients were significantly more likely to receive these explanations than repeat visit clients.

Table 7.3 Proportion of clients provided information about specimen taken and medications given by type of clinic

\begin{tabular}{|l|ccc|cc|}
\hline & \multicolumn{2}{|c|}{ Intervention } & \multicolumn{2}{c|}{ Comparison } \\
\hline Given information about... & Baseline & Endline & Baseline & Endline \\
\hline Purpose of urine specimen & 43 & 33 & 27 & 21 \\
\hline Purpose of blood specimen & 80 & 69 & 58 & 52 \\
\hline Purpose of iron/ferrous sulphate tablets & 93 & $59^{\star \star \star}$ & 68 & $51^{\star}$ \\
\hline How to take the tablets & 95 & 88 & 94 & 90 \\
\hline Purpose of ATT injection & 86 & $47^{\star \star \star}$ & 48 & 59 \\
\hline
\end{tabular}

Note: $*=\mathrm{P}<.05 ; * * *=\mathrm{P}<.001$ 


\subsubsection{Nutrition and Birth Preparedness Advice}

The proportion of clients receiving advice on nutrition during pregnancy reduced slightly in intervention clinics (48\% to 43\%), and significantly in the comparison clinics (from $60 \%$ to 24\%). As shown in Figure 7.1 aspects of birth planning were not well covered generally, and although the intervention improved the provision of information about skilled attendance and advice on which items to have at home, discussing where to deliver reduced tremendously over time, but increased in the comparison clinics.

\section{Figure 7.1 Proportion of first visit clients with whom providers discussed aspects of a} delivery plan

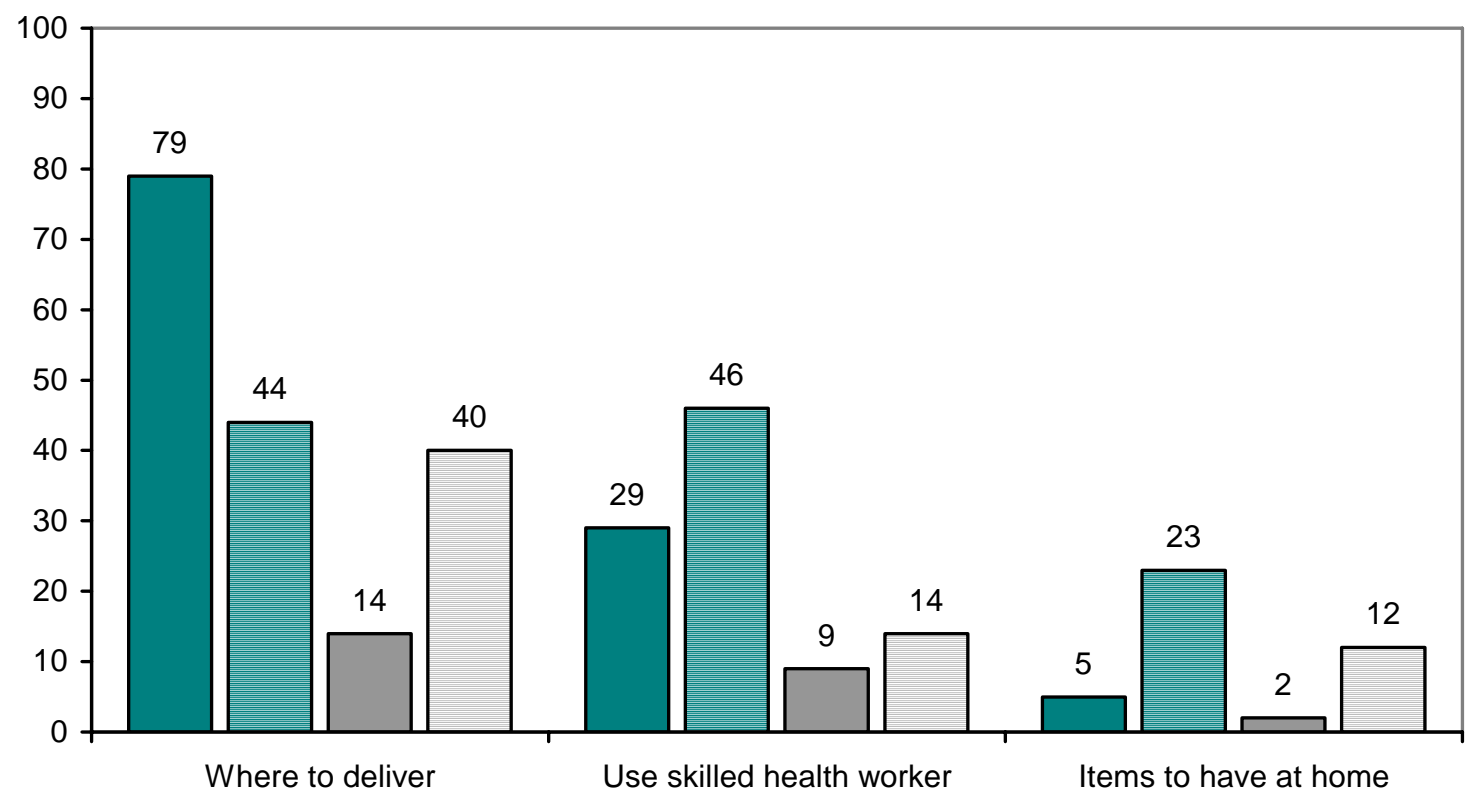

$$
\begin{array}{ll}
\square \text { Intervention baseline }(n=57) & \text { 目 Intervention endline }(n=52) \\
\square \text { Comparison baseline }(n=64) & \square \text { Comparison endline }(n=50)
\end{array}
$$

\subsubsection{Breastfeeding counselling}

As Table 7.4 indicates, although there were significant increases in the proportion of clients with whom the provider discussed various breastfeeding options at endline in all clinics, these proportions remained worryingly low. There were no significant differences between the intervention and comparison clinics. Providers were significantly more likely to have discussed breastfeeding with first visit than with return visit clients at baseline, but there was no difference at endline. 
Table 7.4 Proportion of clients with whom the provider discussed breastfeeding options

\begin{tabular}{|c|c|c|c|c|}
\hline & \multicolumn{2}{|c|}{ Intervention } & \multicolumn{2}{|c|}{ Comparison } \\
\hline & Baseline & Endline & Baseline & Endline \\
\hline Exclusive breastfeeding & 7 & 15 & 9 & $22^{\star *}$ \\
\hline Exclusive substitute feeding & 3 & 8 & 0 & $14^{\star \star \star}$ \\
\hline Mixed feeding & 1 & 5 & 2 & $13^{\star \star}$ \\
\hline Any breastfeeding option & 7 & $16^{*}$ & 9 & $24^{\star \star}$ \\
\hline
\end{tabular}

\subsubsection{Counselling on postpartum family planning}

Less than half of all clients received any counselling on postpartum family planning, although there was a significant increase in the comparison clinics over time. Injectables and pills were the methods most frequently discussed. First visit clients were significantly $(p=.001)$ more likely than repeat clients to receive postpartum FP counselling.

Table 7.5 Proportion of clients with whom the provider discussed various family planning methods

\begin{tabular}{|l|cc|cc|}
\hline & \multicolumn{2}{|c|}{ Intervention } & \multicolumn{2}{c|}{ Comparison } \\
\hline & Baseline & Endline & Baseline & Endline \\
\hline Discussed FP & 43 & $29^{*}$ & 32 & $52^{\star *}$ \\
\hline Injectables & 39 & 27 & 26 & 36 \\
\hline Pills & 22 & 19 & 20 & 22 \\
\hline Male condom & 12 & 10 & 13 & 13 \\
\hline IUD & 4 & $8^{*}$ & 10 & 5 \\
\hline Lactational amenorrhoea method (LAM) & 5 & 0 & 3 & 0 \\
\hline Female condom & 2 & 1 & 1 & $11^{* \star *}$ \\
\hline Other & 8 & 7 & 14 & 9 \\
\hline
\end{tabular}

Note: $*=\mathrm{P}<.05 ; * *=\mathrm{P}<.01 ; * * *=\mathrm{P}<.001$

\subsection{Integration of STI prevention and management services}

STI prevention and management were introduced as additional services to the ANC services usually offered; indeed, with the exception of an external genital exam, provision of STI information and counselling was minimal among first visit clients in all clinics at baseline (table 7.6). After the intervention, there was a doubling in the mean number of STI issues discussed (although this increase was not statistically significant), and the intervention clinics had a significantly larger increase (84\%) than the comparison (9\%) clinics in the proportion of first visit clients who received at least one STI-related service - mostly due to increases in examination of external genitalia, discussions of STI symptoms, and the role of condoms. Interestingly, providers in the comparison clinics showed significant increases in four areas, 
but also significant declines in two key areas - pelvic exam and discussing condom use during pregnancy.

Table 7.6 Proportion of first visit clients receiving STI-related information or services

\begin{tabular}{|l|cc|cc|}
\hline \multicolumn{1}{|c|}{ STI related Service } & \multicolumn{2}{|c|}{ Intervention } & \multicolumn{2}{c|}{ Comparison } \\
\hline Pelvic exam & $\begin{array}{c}\text { Baseline } \\
(\mathrm{n}=59)\end{array}$ & $\begin{array}{c}\text { Endline } \\
(\mathrm{n}=53)\end{array}$ & $\begin{array}{c}\text { Baseline } \\
(\mathrm{n}=65)\end{array}$ & $\begin{array}{c}\text { Endline } \\
(\mathrm{n}=49)\end{array}$ \\
\hline Exam of external genitalia & 9 & 8 & 39 & $12^{\star \star}$ \\
\hline Discussed STI symptoms & 55 & $76^{\star}$ & 57 & 59 \\
\hline Provider enquired presence of STI & 10 & $32^{\star *}$ & 9 & $27^{\star}$ \\
\hline Discussed STI risk factors & 14 & 17 & 5 & $29^{\star \star *}$ \\
\hline Enquired client's STI risk factors & 12 & 13 & 11 & $27^{\star}$ \\
\hline Discussed how to prevent STI & 12 & 15 & 0 & $16^{\star \star}$ \\
\hline Discussed role of condom in STI prevention & 19 & 30 & 9 & 18 \\
\hline Provider discussed condom use in pregnancy & 15 & $45^{\star \star \star}$ & 20 & 18 \\
\hline & 22 & 40 & 29 & $4^{\star \star}$ \\
\hline Received at least one STI service & 32 & & & 35 \\
\hline & & & & 32 \\
\hline Mean score & 1.16 & 2.02 & 0.94 & 1.88 \\
\hline Mean score high client load clinics & .62 & 1.71 & .94 & 2.53 \\
\hline Mean score medium client load clinics & 1.80 & 1.29 & 1.59 & 2.00 \\
\hline Mean score low client load clinics & 1.23 & 3.36 & .36 & 0.75 \\
\hline
\end{tabular}

\subsection{Integration of HIV services}

The proportion of first visit clients receiving at least one HIV-related service was low at baseline, but this increased by endline (Table 7.7), with the magnitude of change being greater in the intervention (110\%) than the comparison (42\%) clinics. However, despite these large increases, after the intervention less than half of the pregnant women were getting any HIV service, and only about one-third were being informed about PMTCT. However, over two-thirds of clients reported that a provider had ever discussed PMTCT, VCT or condom use with them, suggesting that these issues are being discussed during other visits.

Support for having an HIV test was high among all clients (77\% baseline, 81\% endline), and slightly higher in the intervention than comparison clinics, but this difference was significant only at endline ( $88 \%$ vs. $74 \%$ ). Only 11 percent of clients had ever had an HIV test at baseline, but this more than doubled to 24 percent by endline. However, comparison clinic clients were more likely than intervention clinic clients, at both baseline (15\% vs. $7 \%)$ and endline (34\% vs. $12 \%$; $\mathrm{p}<.001$ ), to have had an HIV test, and the increase in these proportions was greater in the comparison (127\%) than intervention (71\%) clinics. Thus although clients attending the intervention clinics became more supportive of VCT testing than those attending the comparison clinics, they were actually much less likely to have had a test. 
During the endline survey, clients who had tested for HIV were asked whether this was done, and whether their partners had an HIV test. The majority (92\%) did so when they were pregnant, and only four percent knew that their partners had been tested, the majority (64\%) reporting that their partners had not had an HIV test. This highlights the high levels of couple discordance in knowledge of HIV status that is being created through introducing VCT during pregnancy without sufficient partner engagement.

Table 7.7 Proportion of first visit clients receiving HIV-related information or services

\begin{tabular}{|c|c|c|c|c|}
\hline & \multicolumn{2}{|c|}{ Intervention } & \multicolumn{2}{|c|}{ Comparison } \\
\hline & $\begin{array}{c}\text { Baseline } \\
(n=59)\end{array}$ & $\begin{array}{c}\text { Endline } \\
(n=53)\end{array}$ & $\begin{array}{c}\text { Baseline } \\
(n=65)\end{array}$ & $\begin{array}{l}\text { Endline } \\
(n=49)\end{array}$ \\
\hline Discussed PMTCT & 17 & $36^{*}$ & 9 & $31^{\star \star}$ \\
\hline Discussed advantages of VCT & 17 & 30 & 17 & 32 \\
\hline Discussed where to go for VCT & 10 & $32^{\star \star}$ & 23 & 29 \\
\hline Clients provider referred for VCT & 2 & 11 & 6 & 13 \\
\hline Received at least one HIV service & 20 & 42 & 26 & 37 \\
\hline \multicolumn{5}{|c|}{ Clients' report of HIV services received during this or any other visit } \\
\hline & $\begin{array}{c}\text { Baseline } \\
(n=115)\end{array}$ & $\begin{array}{l}\text { Endline } \\
(n=119)\end{array}$ & $\begin{array}{c}\text { Baseline } \\
(n=126)\end{array}$ & $\begin{array}{l}\text { Endline } \\
(\mathrm{n}=134)\end{array}$ \\
\hline Provider discussed condom use & 26 & $65^{\star \star \star}$ & 44 & 49 \\
\hline Provider discussed PMTCT & 37 & $71^{\star \star \star}$ & 48 & $61^{*}$ \\
\hline Provider discussed VCT & 31 & $71^{* \star *}$ & 41 & $63^{\star \star \star}$ \\
\hline Client referred for VCT & 9 & $33^{\star \star \star}$ & 36 & 47 \\
\hline
\end{tabular}

\section{Clients' and providers' satisfaction}

\subsection{Client satisfaction with services}

More than 90 percent of both intervention and comparison clinic clients expressed satisfaction with being able to discuss their problems with the provider; with providers' explanations about problems and medication given; with the quality of examination and treatment provided; with visual and auditory privacy; and with the way clinic staff treated them. In both groups of clinics, and at baseline and endline, several aspects of the service, including waiting time, availability of medicine, hours of service, and cleanliness of clinics were of concern to clients (see Table 8.1), with little change over time. At baseline, comparison clinic clients were significantly more willing than those attending intervention clinics to refer friends to the facility, and to have ever recommended the facility to a friend, but by endline this had changed dramatically, with clients in the comparison clinics greatly reducing their willingness to make such recommendations. 
Table 8:1 Clients’ satisfaction with clinic services

\begin{tabular}{|c|c|c|c|c|}
\hline & \multicolumn{2}{|c|}{ Intervention } & \multicolumn{2}{|c|}{ Comparison } \\
\hline & $\begin{array}{c}\text { Baseline } \\
(n=115)\end{array}$ & $\begin{array}{l}\text { Endline } \\
(\mathrm{n}=119)\end{array}$ & $\begin{array}{c}\text { Baseline } \\
(n=126)\end{array}$ & $\begin{array}{l}\text { Endline } \\
(n=134)\end{array}$ \\
\hline $\begin{array}{l}\text { Waiting time } \\
\text { Too long } \\
\text { Short }\end{array}$ & $\begin{array}{l}29 \\
13\end{array}$ & $\begin{array}{l}36 \\
22\end{array}$ & $\begin{array}{l}29 \\
33\end{array}$ & $\begin{array}{l}25 \\
16\end{array}$ \\
\hline $\begin{array}{l}\text { Time Waited } \\
\text { Satisfied } \\
\text { Dissatisfied }\end{array}$ & $\begin{array}{l}79 \\
20\end{array}$ & $\begin{array}{l}72 \\
25\end{array}$ & $\begin{array}{l}68 \\
27\end{array}$ & $\begin{array}{l}77 \\
15\end{array}$ \\
\hline $\begin{array}{l}\text { Availability of Medicine } \\
\text { Satisfied } \\
\text { Dissatisfied }\end{array}$ & $\begin{array}{c}84 \\
6\end{array}$ & $\begin{array}{c}85 \\
3\end{array}$ & $\begin{array}{c}91 \\
4\end{array}$ & $\begin{array}{c}75 \\
7\end{array}$ \\
\hline $\begin{array}{l}\text { Hours of service } \\
\text { Satisfied } \\
\text { Dissatisfied }\end{array}$ & $\begin{array}{l}74 \\
20\end{array}$ & $\begin{array}{l}71 \\
11\end{array}$ & $\begin{array}{l}77 \\
13\end{array}$ & $\begin{array}{l}72 \\
16\end{array}$ \\
\hline $\begin{array}{l}\text { Cleanliness } \\
\text { Satisfied } \\
\text { Dissatisfied }\end{array}$ & $\begin{array}{l}85 \\
10\end{array}$ & $\begin{array}{c}90 \\
2\end{array}$ & $\begin{array}{c}97 \\
2\end{array}$ & $\begin{array}{c}88 \\
3\end{array}$ \\
\hline Would recommend other & clients to & ise the $\mathrm{cl}$ & & \\
\hline $\begin{array}{l}\text { Would strongly recommend } \\
\text { Would never recommend }\end{array}$ & $\begin{array}{c}68 \\
7\end{array}$ & $\begin{array}{c}67 \\
7\end{array}$ & $\begin{array}{c}95 \\
3\end{array}$ & $\begin{array}{c}60 \\
7\end{array}$ \\
\hline Has ever recommended someone to the clinic & 33 & 40 & 51 & 28 \\
\hline
\end{tabular}

\subsection{Provider satisfaction}

Figure 7:1 presents providers' reported job satisfaction. The vast majority of providers were moderately or highly satisfied, and over time there was a movement of providers towards reporting being highly satisfied, with a slight decrease in the already small proportion of those reporting being dissatisfied. Providers in the intervention clinics (4/14 baseline; 4/19 endline) were more likely to be dissatisfied with their job than those in the comparison clinics (2/29 baseline and 1/30 endline). 
Fig 8.1 Providers' levels of job satisfaction (cont.)

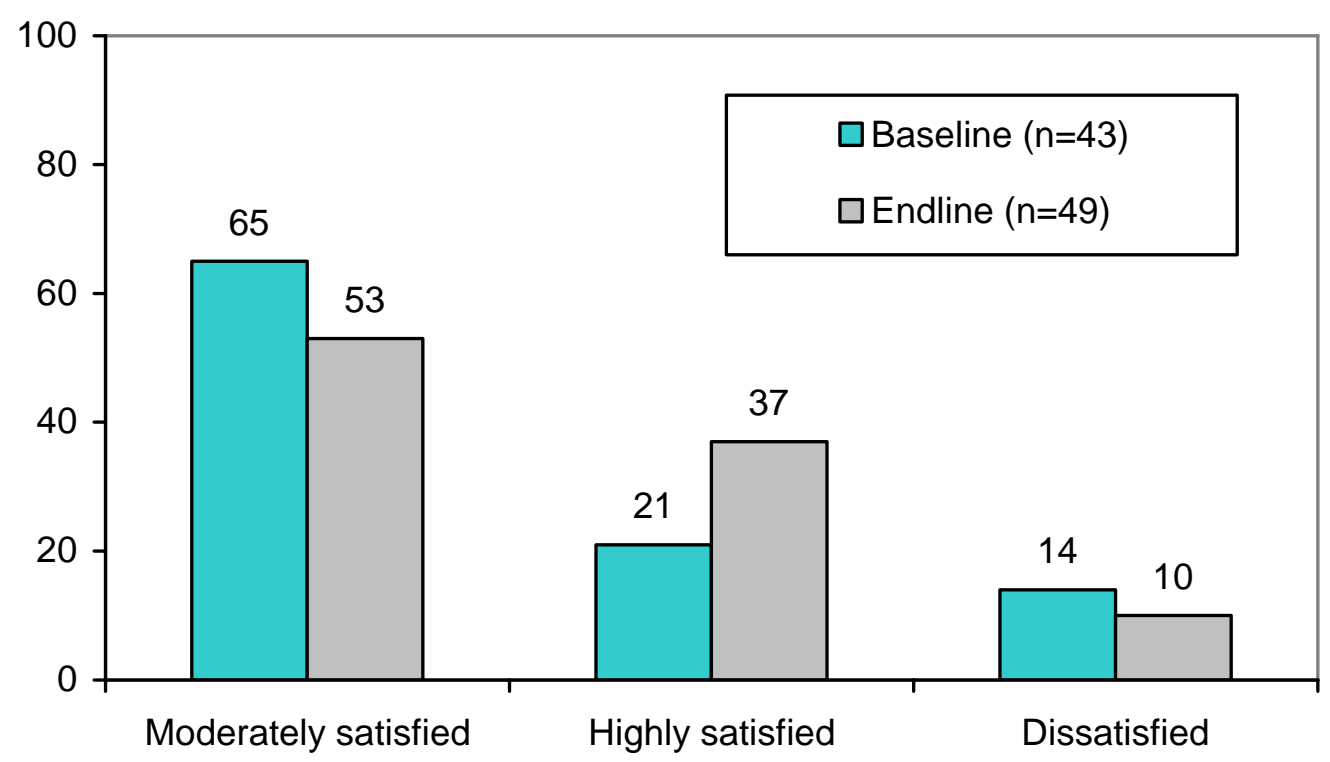

When asked what issues concerned them that they felt should be addressed, understaffing, heavy workload, and a lack of training and equipment were the most frequently identified (Figure 7), but the proportions reporting these issues declined substantially by the endline. Interestingly, less than one-sixth of providers mentioned better pay, an issue that is usually considered an important area of improvement. There were no significant differences between intervention and comparison clinics. 
Figure 8.2 Issues that providers feel should be addressed

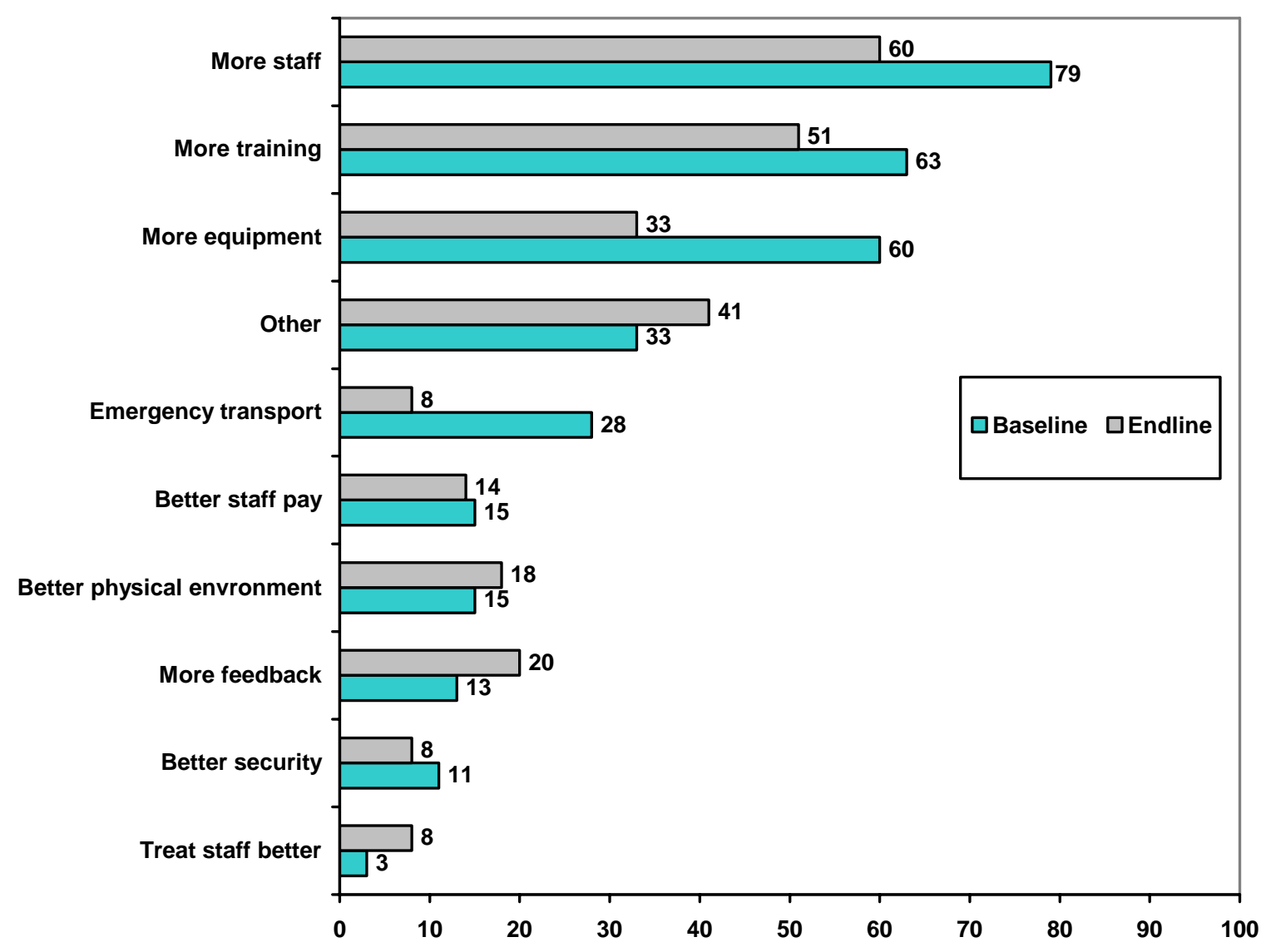

\section{Dissemination and utilization of results}

The baseline and endline survey findings were disseminated to DOH provincial and district managers, supervisors and clinic staff in the intervention district through workshops held in March and August 2003. Workshop participants concurred with the study findings and made recommendations on what should be done to address the observed limitations (see Appendix 2), including the persons responsible for implementing specific recommendations and for monitoring and reporting on progress, as well as a specific timeline for implementation.

The Intervention District DOH management took the study findings and recommendations from the dissemination workshop seriously. The District management team called for a meeting that included clinic supervisors, the MCWH Coordinators and the study Intervention Coordinator to discuss ways of addressing the recommendations. Following these recommendations and follow-up activities emanating from the various meetings with the research team and the dissemination workshop, the KZN DOH implemented the following activities:

- Required service protocols and guidelines were standardized and distributed to the clinics.

- Clinics were requested to provide a list of all missing and faulty equipment. Clinic supervisors were to ensure that these items were supplied to the respective clinics 
- District management provided support to hire vehicles to transport blood specimens from the clinics to the hospital labs twice per week.

- The District hospital labs provided the first set of RPR kits to all six clinics.

- District management ensured continued service provision in the two intervention clinics that were threatened with closure due to staff turnover. District management hired a retired professional nurse midwife to provide services in one clinic and arranged for a registered professional nurse from the hospital to provide ANC services on specific days in the other clinic.

- Transport was provided to some Master Trainers who offered to cascade training in some intervention clinics.

During the dissemination workshop, challenges to implementation and the limitations of the training approach adopted were highlighted. DOH Provincial and District management staff resolved to change the training strategy, train staff and supervisors in all the clinics in the district by end of October 2003, and implement a continuous rather than one-time training strategy. DOH Provincial staff provided training to all hospital-based clinic supervisors in the intervention district and by the last week of October 2003, the majority of the clinics had at least one staff trained in the seven ANC package modules.

\section{Summary and conclusions}

The aims of this study were to assess the feasibility and acceptability of introducing a comprehensive and integrated model for antenatal (and postnatal) care, through adapting the focused ANC model promoted by WHO. The study also sought to determine the impact of reorganizing services on the quality of care and on client and provider satisfaction. Within this overall study, there was a nested study to assess the introduction of on-site maternal syphilis screening, the results of which will be presented in a separate report. In brief, the study produced the following results:

\subsection{Clinic preparedness}

- Facility infrastructure was sufficient to offer ANC services, and most clinics had almost all equipment available in working order. Staffing levels were adequate, but declines in numbers of qualified staff (due to migration) over time compromised the clinics' capacity to offer ANC on a full-time basis, especially in the intervention clinics.

- Supervision and monitoring was insufficient at baseline, and declined by the endline in the intervention clinics.

- Availability of service delivery guidelines increased, but availability of IEC materials decreased in the intervention clinics.

- Availability of essential drugs and other supplies improved and by endline most intervention clinics had most of the necessary supplies. Family planning stockouts were virtually non-existent.

- A summary measure of clinic preparedness shows a significant improvement in the intervention clinics and a non-significant improvement in the comparison clinics. 


\subsection{Quality of services}

- ANC services were available on a daily basis in most clinics, as were STI and FP services. On-site VCT was available in 10 of the 12 clinics by the endline.

- Interpersonal relations were satisfactory, although less than half of the clients at baseline and endline asked or were invited to ask questions.

- Privacy, auditory and visual, was good in all clinics.

- Virtually all providers assessed first visit clients' age and pregnancy status, and performed equally well in conducting routine checks for weight, height, blood pressure, urine analysis, abdominal palpation, foetal heartbeat and Hb testing.

- Most women had blood drawn for syphilis testing on their first visit. Introduction of on-site RPR testing in the intervention clinics led to an increase in same-day receipt of results, but this did not happen for every woman due to inconsistent performance.

- Approximately 90 percent of first visit clients received folic acid and iron supplements at baseline and endline. There was a significant increase over time so that by endline over three-quarters of clients in intervention clinics received tetanus toxoid.

- The proportion of clients informed about specimens taken and medication provided decreased significantly over time in the intervention clinics.

- First visit clients were significantly more likely than repeat clients to be assessed for and receive counselling on pregnancy danger signs.

- The proportions of first visit clients who were assessed for at least one pregnancy danger sign increased slightly over time, but the mean number of danger signs assessed reduced significantly in intervention clinics. Women were counselled on less than two out of a possible eight signs.

- Counselling women on nutrition in pregnancy and on birth planning were insufficient, and changed little after the intervention.

- At endline, less than one-fifth of clients in intervention clinics were counselled on breastfeeding, although this represents significant increases over the baseline.

- At endline, less than 30 percent of clients in intervention clinics were counselled on postpartum family planning, and this proportion had decreased significantly from the baseline. Over the same time, there was a significant increase in the comparison clinics.

- The proportion of clients in intervention clinics receiving at least one STI service almost doubled to 59 percent by the endline survey. Although there were significant increases in external genital exams, discussion of STI symptoms and condom use for STI prevention, there was no increase in assessing a client's risk or presence of symptoms.

- Likewise, the proportion of clients in intervention clinics receiving at least one HIV service more than doubled to 42 percent by the endline survey, although there was also a sizeable increase in the comparison clinics. Even though there were significant increases, two-thirds of pregnant women were still not being counselled about PMTCT or VCT at endline. 
- The vast majority (87\%) of providers were moderately or highly satisfied with their job and there was little change over time. Those issues that they felt did need to be addressed were primarily additional staff and more training; by the endline, concerns about inadequate equipment had reduced considerably.

- Most clients expressed satisfaction with most aspects of the service received, the only issue of real concern being long waiting times.

\subsection{Conclusions}

As discussed in Section 3, while introduction of the intervention activities themselves was feasible, numerous problems were encountered, during and immediately afterwards, that influenced the clinics' capacity to implement and sustain the re-organized services, such as: trainer and staff turnover; inadequate logistics and budgetary planning; and insufficient involvement of key stakeholders. This finding implies that efforts to scale-up or replicate this model throughout the province, and elsewhere in South Africa or sub-Saharan Africa, must consider such resource and systems issues during the planning and budgeting phase.

Moreover, other support systems, such as staff supervision and educational materials, also need attention alongside strengthening more obvious systems such as training, equipment and supplies. It was clearly not an easy intervention to introduce and sustain in this type of environment.

One concern prior to its introduction was the effect it would have on provider and client satisfaction with ANC services. As the results show, overall there was no detrimental effect on staff morale; indeed, improvements in clinic preparedness to offer ANC services reduced some of the staff concerns about their working conditions. Client satisfaction was already quite high and did not improve further following the intervention.

The focus of the intervention was two-fold: strengthening the clinic and staff's capacity to offer the routine set of antenatal care services that are intended to monitor progress in pregnancy and to reduce maternal morbidity; and providing additional services that would enhance a safe pregnancy and address pregnant women's other reproductive health needs and behaviours. The results indicate that the straightforward services for monitoring and managing the physical progress of the pregnancy (including specimen collection and provision of medications) were already being provided satisfactorily, and that these were sustained, although there was a significant decrease in giving women appropriate information about these services. There were, however, some notable exceptions, primarily in terms of counselling services. Thus, the proportions of women receiving counselling on nutrition in pregnancy, on birth planning, on breastfeeding and on postpartum family planning were insufficient at endline, even though there may have been some increases attributable to the intervention. Of particular concern is the finding that even though the proportion of first visit clients who were assessed for at least one pregnancy danger sign increased slightly over time, the mean number of danger signs assessed reduced significantly in the intervention clinics, with women being counselled on less than two out of a possible eight signs.

Among the additional services offered, the proportion of ANC clients receiving STI and/or HIV services doubled in the intervention clinics. However, the proportions of women receiving these services remained well below the universal coverage expected; of particular concern is the fact that less than one-third of pregnant women were informed about PMTCT and VCT, despite rollout of the national PMTCT programme at the same time as this intervention. Moreover, the content of the additional services provided in the intervention clinics primarily included an external genital exam, discussion of STI symptoms and condom Feasibility of introducing a comprehensive integrated package of antenatal care services in rural public clinics in South Africa 
use for STI prevention - there was no increase in assessing a client's personal risk for STIs, including presence of symptoms (although these did increase in the comparison clinics). Introduction of the on-site syphilis testing also suffered some setbacks, but once introduced, preliminary results suggest that this service appears to have been sustained.

Although these results are clearly disappointing, it is important to bear in mind that despite the intervention activities being introduced pretty much according to plan, immediate staff turnover and inadequate supervision meant that only two of the six intervention clinics had at least one staff member who had covered all the training modules at the time of the endline survey. As staff were either not being replaced, or their replacements not trained in the new ANC model, it is not possible, or valid therefore, to conclude from these findings whether implementation of the intervention did or did not improve the quality of care. This is because, following its introduction, staffing problems meant that the intervention could not be implemented as intended.

It is possible to conclude, however, that interventions such as this, that rely heavily on training staff in new ways of organizing and providing services, must develop and use training and supervisory strategies or systems that are explicitly designed to incorporate relatively rapid rates of staff turnover. This may mean developing the capacity of the clinic staff, or of the supervisor responsible for monitoring ANC services in the clinic, to ensure that if a trained staff member leaves someone either replaces them that has the same technical competence, or the replacement undergoes immediate training in the ANC model being implemented at that clinic. This study also highlights the importance of paying attention to health systems when introducing revised or new services, especially HIV-related services. 


\section{REFERENCES}

Auvert B, Buve A, Ferry B, et al. 2001. Ecological and individual level analysis of risk factors for HIV infection in four urban populations in sub-Saharan Africa with different levels of HIV infection. AIDS 2001, 15 (suppl 4) S15-S30).

Buve A, Weiss H. A, Laga M, et al. 2001. The epidemiology of trichomoniasis in women in four African cities. AIDS 2001, 15 (suppl 4) S89-S96).

Cameron DW, Simonsen JN, D’Costa LJ, et al. 1989. Female to male transmission of human immunodeficiency virus type 1: risk factors for seroconversion in men. Lancet 1989;334:403-7.

Carroli, G. et. al. 2001. "WHO systematic review of randomised controlled trials of routine antenatal care” Lancet 2001; 357: 1565-70.

Department of Health. 2000. Guidelines for Maternity Care in South Africa: A Manual for Clinics, Community Health Centres and District Hospitals. P 23.

Department of Health. 2000. Third Interim Report on Confidential Enquiries into Maternal Deaths in South Africa.

Department of Health. 2003. Operational Plan for Comprehensive HIV and AAAAIDS Care, Management and Treatment for South Africa. 19 $9^{\text {th }}$ November 2003.

Fleming D, Wasserheit J. 1999. From epidemiological synergy to public health policy and practice: the contribution of other sexually transmitted diseases to sexually transmission of HIV infection. Sex Transm Inf 1999; 75:3-17.

Grosskurth H, Mosha F, Todd J, et al. 1995. Impact of improved treatment of sexually transmitted diseases on HIV infection in rural Tanzania: randomised controlled trial. Lancet 1995, 346:530-536.

KwaZulu-Natal Department of Health. (KZN-DOH) 1998. Care of Pregnant Women and Newborns at Clinic and District Level.

Maine D. 1991. Safe motherhood programs: options and issues. New York, Columbia University.

Nelson Mandela/HSRC Study of HIV/AIDS 2002: South African National HIV Prevalence, Behavioural Risks and Mass Media Household Survey

Saving Babies 2000. A Perinatal Care Survey of South Africa. MRC Unit for Maternal and Infant Health Care Strategies, PPIP Users, and the National Department of Health.

Saving Mothers. Report on Confidential Enquiries into Maternal Deaths in South Africa 1998. Department of Health. ISBN 1-875017-35-6.

Saving Mothers. 1999-2001. Second Report on Confidential Enquiries into Maternal Deaths in South Africa 1999-2001. Department of Health. ISBN 1-875017-80-1

Villar, J. et al. 2001. "WHO antenatal randomised trial for the evaluation of a new model of routine antenatal care” The Lancet, 357: 1551-64.

WHO and UNICEF. 2003. Antenatal Care in Developing Countries: Promises, Achievements and Missed Opportunities. WHO Library Cataloguing-in-Publication Data ISBN 924 1590947. 


\section{Appendix 1: Characteristics of Providers and Clients}

\section{Socio-demographic Characteristics of the Providers}

\begin{tabular}{|c|c|c|}
\hline Characteristic & Baseline $(n=43)$ & Endline $(n=49)$ \\
\hline Male & 4 & 7 \\
\hline Female & 39 & 42 \\
\hline \multicolumn{3}{|l|}{ Years of Schooling } \\
\hline $10-11$ & 4 & 15 \\
\hline 12 & 35 & 25 \\
\hline $13-18$ & 4 & 8 \\
\hline Registered nurse with midwifery & 26 & 19 \\
\hline Registered nurse without midwifery & 2 & 2 \\
\hline Registered midwife & 1 & 2 \\
\hline Enrolled nurse & 2 & 10 \\
\hline Enrolled nurse assistant & 2 & 4 \\
\hline Student nurse/ metric & 9 & 12 \\
\hline \multicolumn{3}{|l|}{ Number of years since graduation* } \\
\hline $1-2$ & 7 & 8 \\
\hline $3-5$ & 7 & 5 \\
\hline $6-9$ & 6 & 6 \\
\hline $12-22$ & 7 & 7 \\
\hline $24-41$ & 8 & 11 \\
\hline Mean & 13.18 & 15.00 \\
\hline \multicolumn{3}{|l|}{ Number of years worked at facility* } \\
\hline 1 year & 10 & 19 \\
\hline $2-3$ & 5 & 5 \\
\hline $4-5$ & 10 & 2 \\
\hline $6-29$ & 7 & 11 \\
\hline Mean & 5.81 & 5.57 \\
\hline
\end{tabular}

* Excluding student nurses ( $\mathrm{n}=32$ baseline, $\mathrm{n}=44$ endline) 
Percentage distribution of socio-demographic characteristics of clients and gestation age at first visit by site

\begin{tabular}{|c|c|c|c|c|}
\hline \multirow[t]{2}{*}{ Characteristics } & \multicolumn{2}{|c|}{ Baseline } & \multicolumn{2}{|c|}{ Endline } \\
\hline & $\begin{array}{c}\text { Intervention } \\
(n=115)\end{array}$ & $\begin{array}{c}\text { Comparison } \\
(n=126)\end{array}$ & $\begin{array}{c}\text { Intervention } \\
(n=119)\end{array}$ & $\begin{array}{c}\text { Comparison } \\
(n=134)\end{array}$ \\
\hline Age & & & & \\
\hline Mean & 24.78 & 24.95 & 23.87 & 24.49 \\
\hline Median & 22.50 & 23.00 & 22.00 & 23.50 \\
\hline $15-19$ & 24 & 22 & 29 & 31 \\
\hline $20-24$ & 33 & 36 & 34 & 23 \\
\hline $25-29$ & 19 & 19 & 19 & 19 \\
\hline $30+$ & 24 & 23 & 19 & 28 \\
\hline Education & & & & \\
\hline No schooling & 8 & $22^{\star *}$ & 4 & $22^{\star \star \star}$ \\
\hline Primary school & 23 & 21 & 12 & 18 \\
\hline Secondary + & 70 & 57 & 85 & 60 \\
\hline Marital Status & & & & \\
\hline Unmarried not cohabiting & 75 & $54^{\star \star}$ & 65 & 52 \\
\hline Unmarried cohabiting & 15 & 37 & 20 & 30 \\
\hline Ever Married & 10 & 10 & 15 & 18 \\
\hline First pregnancy & 42 & 41 & 44 & 41 \\
\hline Occupation & & & & \\
\hline Housewife/unemployed & 59 & 70 & 52 & 61 \\
\hline Salaried & 7 & 10 & 8 & 7 \\
\hline Small scale trader & 23 & 11 & 11 & 13 \\
\hline Student & 9 & 6 & 23 & 16 \\
\hline Other & 3 & 4 & 7 & 3 \\
\hline Gestation Age at $1^{\text {st }}$ Visit & $(n=55)$ & $(n=61)$ & $(n=53)$ & $(n=49)$ \\
\hline $1^{\text {st }}$ trimester (1-12 weeks) & 7 & 8 & 9 & 8 \\
\hline $2^{\text {nd }}$ trimester (13-24 weeks) & 67 & 61 & 74 & 71 \\
\hline $3^{\text {rd }}$ trimester (25-36 weeks) & 26 & 31 & 17 & 20 \\
\hline 4-20 weeks & 58 & 43 & 55 & 57 \\
\hline $21+$ weeks & 42 & 57 & 45 & 43 \\
\hline Mean & 21.31 & 22.62 & 21.00 & 21.71 \\
\hline Median & 20.00 & 24.00 & 20.00 & 20.00 \\
\hline
\end{tabular}





\section{Appendix 2: Recommendations From Dissemination Workshop Participants}

- Standardization of ordering levels for supplies, drugs, and contraceptives

- Development of policies and procedures for repair of equipment to be adopted by all clinics

- Orientation for all clinic staff on standard of equipment required in clinics

- In-service clinic-based training on proper use of equipment

- Improved salaries and working conditions for staff and establishment of a recruitment allowance for rural areas

- Provision of dedicated transport for trainers to facilitate cascading of the training

- Having dedicated trainers who are not provided with clinic service provision responsibilities

- Involving supervisors in decision-making about staff transfers

- Ensure proper staffing in all clinics

- Provide dedicated transport for supervisors to improve supervision

- Provide incentives to avoid resistance to move and work

- Budget for RPR kits to be discussed. Technologist in-charge of hospital labs to ensure that all study clinics have RPR kits

- Human resources department to employ people who will do the on-site RPR testing instead of burdening the over-worked clinic-based nurses

- District management to address transport issues to ensure that all clinics send specimens to the hospital lab (study clinics for quality control, other clinics for RPR test) at least once in a week 


\section{Appendix 3: Key Indicators}

\begin{tabular}{|c|c|c|c|c|}
\hline \multirow[t]{2}{*}{ Characteristics } & \multicolumn{2}{|c|}{ Baseline } & \multicolumn{2}{|c|}{ Endline } \\
\hline & Int. & Comp. & Int. & Comp. \\
\hline \multicolumn{5}{|c|}{ Client Behaviours } \\
\hline Never used condom with partner & 92 & 91 & 84 & 85 \\
\hline Sex with another man past 6 months & 4 & 1 & 3 & 1 \\
\hline Think there is need for HIV testing & 78 & 76 & 88 & $74^{\star \star}$ \\
\hline Had HIV test & 7 & 15 & 12 & $34^{\star \star \star}$ \\
\hline Test for HIV when pregnant & & & 79 & 96 \\
\hline Partner tested for HIV? Yes & & & 7 & $2^{\star \star *}$ \\
\hline Partner tested for HIV? Don't know & & & 22 & 40 \\
\hline \multicolumn{5}{|c|}{ Services Provided: First and Repeat Visit Clients } \\
\hline Provider great client & 84 & $96^{\star \star}$ & 94 & 96 \\
\hline Provider introduce self to client & 38 & $58^{\star \star}$ & 72 & 63 \\
\hline Ensure privacy (audio and visual) & 96 & 97 & 88 & $96^{*}$ \\
\hline Inform client progress of pregnancy & 84 & 78 & 56 & 52 \\
\hline Encouraged client to ask questions & 31 & $45^{\star}$ & 26 & $44^{\star *}$ \\
\hline Current pregnancy risk assessment - bleeding & 34 & $9^{\star \star \star}$ & 5 & $14^{\star}$ \\
\hline Current pregnancy risk assessment- vaginal discharge & 48 & $33^{\star}$ & 20 & $54^{\star \star \star}$ \\
\hline Current pregnancy risk assessment- medication taking & 46 & 39 & 22 & $34^{*}$ \\
\hline Current pregnancy risk - ask felt baby move & 65 & 69 & 50 & $86^{\star \star \star}$ \\
\hline Current pregnancy risk - ask any problem related & 60 & 62 & 52 & $73^{\star \star \star}$ \\
\hline At least 1 current pregnancy risk assessed & 75 & 85 & 74 & $96^{\star \star \star}$ \\
\hline Counselling pregnancy danger signs: vaginal bleeding & 34 & $20^{\star \star \star}$ & 19 & $4^{\star \star \star}$ \\
\hline Counselling pregnancy danger signs: fever & 19 & $0^{\star \star \star}$ & 8 & 16 \\
\hline Counselling pregnancy danger signs: tired/breathless & 19 & $4^{\star \star \star}$ & 8 & $19^{*}$ \\
\hline $\begin{array}{l}\text { Counselling pregnancy danger signs: swollen } \\
\text { hand/face }\end{array}$ & 26 & $49^{\star \star \star}$ & 23 & 28 \\
\hline $\begin{array}{l}\text { Counselling pregnancy danger signs: severe } \\
\text { headache }\end{array}$ & 27 & $5^{\star \star \star}$ & 16 & $40^{\star \star \star}$ \\
\hline Counselling pregnancy danger signs: water gash & 10 & 18 & 17 & $46^{\star \star \star}$ \\
\hline Counselling pregnancy danger signs: smelly discharge & 5 & 10 & 10 & 9 \\
\hline Counselling on at least 1 danger sign & 55 & 62 & 41 & 49 \\
\hline Weight taken & 99 & 98 & 99 & 100 \\
\hline Blood pressure & 100 & 98 & 100 & 99 \\
\hline Abdomen palpation for foetal presentation & 98 & 98 & 97 & 99 \\
\hline Listen to abdomen for foetal heartbeat & 93 & 96 & 94 & 96 \\
\hline Take Urine specimen & 93 & 97 & 98 & 100 \\
\hline Given iron/folic acid supplements & 90 & $80^{*}$ & 74 & 81 \\
\hline Delivery plan: Where to deliver & 68 & $16^{\star \star \star}$ & 42 & 43 \\
\hline Delivery plan: Use skilled health worker & 27 & $8^{\star \star \star}$ & 39 & $22^{\star \star}$ \\
\hline Delivery plan: Items to have at hand & 5 & 2 & 19 & 15 \\
\hline Discussed delivery plan - at least 1 item & 70 & $23^{\star \star \star}$ & 54 & 44 \\
\hline Breastfeeding counselling: exclusive breastfeeding & 7 & 9 & 15 & 22 \\
\hline
\end{tabular}

Feasibility and effectiveness of a comprehensive integrated package of antenatal care services in rural public clinics in South Africa 


\begin{tabular}{|c|c|c|c|c|}
\hline \multirow[t]{2}{*}{ Characteristics } & \multicolumn{2}{|c|}{ Baseline } & \multicolumn{2}{|c|}{ Endline } \\
\hline & Int. & Comp. & Int. & Comp. \\
\hline Breastfeeding counselling: substitute milk & 3 & 0 & 8 & 14 \\
\hline Breastfeeding counselling: mixed feeding & 1 & 2 & 5 & 13 \\
\hline Counselled on breastfeeding - at least 1 & 7 & 9 & 16 & 24 \\
\hline Discussed nutrition in pregnancy & 48 & 60 & 43 & $25^{\star *}$ \\
\hline \multicolumn{5}{|c|}{ Services Provided: First Visit Clients Only } \\
\hline Enquire age of client & 97 & 95 & 90 & 100 \\
\hline Enquire date of last menstrual period & 95 & 98 & 94 & 100 \\
\hline Enquire number of previous pregnancies & 95 & 88 & 83 & 92 \\
\hline Withdraw blood for syphilis screening & 90 & 92 & 90 & 88 \\
\hline Withdraw blood for HB & 91 & 95 & 92 & 90 \\
\hline Assess need for TT injection & 67 & 72 & 48 & 59 \\
\hline Give anti-tetanus injection & 64 & 72 & 89 & 78 \\
\hline Discuss post-partum FP & 57 & 47 & 40 & $76^{\star \star \star}$ \\
\hline FP methods discussed: LAM & 7 & 3 & 0 & 0 \\
\hline FP methods discussed: Pills & 33 & 31 & 29 & 35 \\
\hline FP methods discussed: Male condom & 16 & 17 & 17 & 14 \\
\hline FP methods discussed: Female condom & 2 & 0 & 2 & $16^{*}$ \\
\hline FP methods discussed: Injectables & 50 & 38 & 37 & 55 \\
\hline FP methods discussed: IUCD & 7 & 17 & 8 & 10 \\
\hline FP methods discussed: Other (abstinence and TL) & 13 & $22^{\star \star \star}$ & 6 & 6 \\
\hline Provider used FP visual aids to counsel & 4 & 0 & 17 & 18 \\
\hline Provided information on MTCT of HIV & 18 & 9 & 35 & 31 \\
\hline Discussed where to go for VCT & 11 & 23 & 31 & 29 \\
\hline Provider enquired client's interest in getting VCT & 7 & 8 & 19 & 31 \\
\hline Infection prevention: & & & & \\
\hline Provider washed hands only & 19 & 0 & 14 & $11^{*}$ \\
\hline Put on gloves only & 19 & 43 & 34 & 23 \\
\hline Washed hands and put on gloves & 21 & 20 & 22 & 49 \\
\hline Did not wash hands or put on gloves & 40 & 37 & 31 & 18 \\
\hline \multicolumn{5}{|c|}{ Client Satisfaction With Services } \\
\hline Ability to discuss pregnancy concerns: Satisfied & 93 & 98 & 93 & 92 \\
\hline Ability to discuss pregnancy concern: Dissatisfied & 6 & 1 & 3 & 2 \\
\hline Explanations provider gave: Satisfied & 95 & 98 & 97 & 91 \\
\hline Explanations provider gave: Dissatisfied & 2 & 2 & 1 & 3 \\
\hline Quality of examination and treatment: Satisfied & 100 & 95 & 95 & 90 \\
\hline Quality of examination and treatment: Dissatisfied & 0 & 3 & 1 & 1 \\
\hline Visual privacy: Satisfied & 98 & 99 & 95 & 94 \\
\hline Visual privacy: Dissatisfied & 1 & 0 & 2 & 2 \\
\hline Audio privacy: Satisfied & 94 & 99 & 89 & 87 \\
\hline Audio privacy: Dissatisfied & 4 & 0 & 3 & 4 \\
\hline Availability of medicines at facility: Satisfied & 84 & 91 & 85 & 75 \\
\hline Availability of medicines at facility: Dissatisfied & 6 & 4 & 3 & 7 \\
\hline How clinic staff treated you: Satisfied & 96 & 99 & 95 & 95 \\
\hline How clinic staff treated you: Satisfied & 2 & 0 & 1 & 2 \\
\hline
\end{tabular}

Feasibility and effectiveness of a comprehensive integrated package of antenatal care services in rural public clinics in South Africa 


\section{Appendix 4: Field Data Collection Team}

\section{Baseline Survey}

Nzwakie Mosery -Supervisor

Jabu Hlazo -Supervisor

Nosipho Ngcobo

Hildegard Ngcobo

Norah Mathe

Nonhlanhla Tseku

Adelaide Kubheka

Wonderboy Nkuku

Busisiwe Zulu

Celiwe Khumalo

Nozipho Makhanya

Khosi Makhubo

Nombuso Zuma

Nonhlanhla Tseku

\section{Endline Survey}

Nonhle Mntungwa - Supervisor

Ntuthuko Khumalo - Supervisor

Mbali Nxumalo - Supervisor

Ntokozo Khuzwayo - Supervisor

Nonhlanhla Tseku

Thembi Mncube

Nkosingiphile Mthembu

Duduzile Mtambo

Adelaide Kubheka

Gugu Dumisa

Bongiwe Ntsuntsha

Sizakele Madondo

Sphumele Thango

Zodwa Buthelezi

Nombuso Zuma

Sibusiso Mazibuko 